WSRC-TR-2000-00488

\title{
Wind Conditions and Flow around Windbreaks at SRS(U)
}

Westinghouse Savannah River Company Savannah River Site

Aiken, SC 29808

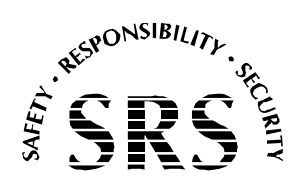

Prepared for the U.S. Department of Energy under Contract No. DE-AC09-96SR18500 
This document was prepared in conjunction with work accomplished under Contract No.

DE-AC09-96SR18500 with the U.S. Department of Energy.

\section{DISCLAIMER}

This report was prepared as an account of work sponsored by an agency of the United States Government. Neither the United States Government nor any agency thereof, nor any of their employees, makes any warranty, express or implied, or assumes any legal liability or responsibility for the accuracy, completeness, or usefulness of any information, apparatus, product or process disclosed, or represents that its use would not infringe privately owned rights. Reference herein to any specific commercial product, process or service by trade name, trademark, manufacturer, or otherwise does not necessarily constitute or imply its endorsement, recommendation, or favoring by the United States Government or any agency

thereof. The views and opinions of authors expressed herein do not necessarily state or reflect those of the United States Government or any agency thereof.

This report has been reproduced directly from the best available copy.

Available for sale to the public, in paper, from: U.S. Department of Commerce, National Technical Information Service, 5285 Port Royal Road, Springfield, VA 22161, phone: (800)

553-6847, fax: (703) 605-6900, email: orders@ntis.fedworld.gov online ordering: http://www.ntis.gov/ordering.htm

Available electronically at http://www.doe.gov/bridge

Available for a processing fee to U.S. Department of Energy and its contractors, in paper, from: U.S. Department of Energy, Office of Scientific and Technical Information, P.O. Box 62, Oak Ridge, TN 37831-0062, phone: (865 ) 576-8401, fax: (865) 576-5728, email: reports@ adonis.osti.gov 


\section{Contents}

Executive Summary 1

I. Statistical Studies 2

A. Statistical Results Based on Maximum Wind Gusts 2

B. Statistical Results Based on 15-Minute-Averaged Wind Speeds 4

C. Correlation of 15-min-Averaged Wind Speeds and Peak Wind Gusts 5

D. Changes of Statistics of 15-Minute Mean Wind, Gust, $\sigma_{\mathrm{A}}$ and $\sigma_{\mathrm{E}}$ with Time 7

E. Approximate Statistical Model for the Distribution of 15-minute

Averaged Speeds for the 5-year Period 12

II. Results from Previous Fluid Modeling Studies Having Relevance to Wind Flow and Dispersion Around Terrain Obstacles and Windbreaks at the High Level Waste Tank Farm 13

A. Requirements for Validity of Wind Tunnel Studies $\mathbf{1 3}$

B. Flow Patterns over a Three-Dimensional Hill in a Stratified Fluid

Topography and Berm Heights 14

C. Flow over Bluff Bodies Such as Windbreaks 17

D. Formulas for Determining Cavity Dimensions behind a Building 17

E. Wind Tunnel Simulations of Block-Building Shapes and Verification of

Hosker's Results 19

F. Numerical Simulation Results for Block-Body Shapes with Open Roofs 20

III. Conclusions 23

IV. References 24 


\section{List of Figures}

Figure 1. $\quad$ Distribution of Peak Gusts for Five Years (1995-99) from the Central Climatology 4meter Level (1-35 mph). 27

Figure 2. $\quad$ Distribution of Peak Gusts for Five Years (1995-99) from the Central Climatology 4meter Level (37-99mph). 28

Figure 3. Cumulative Distribution of Peak Gusts for Five Years (1995-99) from the Central Climatology 4-meter Level. 29

Figure 4. $\quad$ Distribution of 15-min Averaged Speed for Five Years (1995-99) from the Central Climatology 4-meter Level (1-35 mph). 30

Figure 5. Distribution of Extreme 15-min Averaged Wind Speed for Five Years (1995-99) from the Central Climatology 4-meter Level (18-80 mph). 31

Figure 6. Cumulative Distribution of 15-min Averaged Wind Speed for Five Years (1995-99) from the Central Climatology 4-meter Level. 32

Figure 7. Distribution of 15-min Averaged Speeds by Season (Central Climatology 4-m level, 9599). 33

Figure 8. Distribution of 15-min Averaged Speeds by Time of Day (Central Climatology 4-m level, 95-99). 34

Figure 9. Distribution of 15-min Averaged Speeds by Season and Time-of-day (Central Climatology 4-m level, 95-99). 35

Figure 10. $\quad$ Froude Number Distribution. 36

Figure 11. $\quad$ Froude Number by Season and Time of Day. 37

Figure 12. Streamline patterns around a bluff body exposed to the incident wind. From Hosker (1984) (with permission). 38

Figure 13. Mean streamline patterns around a rectilinear building where the crosswind width (W) of the building is varied. From Snyder and Lawson (1996) (with permission). 39

Figure 14. Mean streamline patterns around a rectilinear building where the along-wind depth (D) of the building is varied. From Snyder and Lawson (1996) (with permission). 40

Figure 15. Mean streamline patterns where the height $(\mathrm{H})$ of the building is varied (upper 3 panels). Cubical building at $90^{\circ}$ and $45^{\circ}$ (lower 2 panels) with respect to the upwind flow. From Snyder and Lawson (1996) (with permission). 41

Figure 16. Boundary conditions for driven cavity flow. 42

Figure 17. Driven cavity flow (wind over a cubical windbreak). Flow visualization using temperature. $\mathbf{4 3}$

Figure 18. An open-roofed cavity with height to depth ratio 1/1. Flow visualization using temperature. 44

Figure 19. An open-roofed cavity with height to depth ratio 1/1. Flow visualization using isotherms. 45

Figure 20. An open-roofed cavity with height to depth ratio 2/1. Flow visualization using temperature. 46

Figure 21. An open-roofed cavity with height to depth ratio 2/1. Flow visualization using isotherms. 47

Figure 22. An open-roofed cavity with height to depth ratio 4/1. Flow visualization using temperature. 48

Figure 23. An open-roofed cavity with height to depth ratio 4/1. Flow visualization using isotherms. 49 


\section{List of Tables}

Table I. Percentage Increase in the Number of Cases of 15-minute periods with Peak Wind Gusts in the Range Indicated Over Those at 10-mph. 3

Table 2. Percentage Increase in the Number of Cases of 15-minute periods with 15-Minute-Averaged Wind Speeds Less Than the Speed Indicated Over Those at 10-mph. 5

Table 3. Regression Analysis Parameters by Daytime and Nighttime for Predicting the Peak Gust from the 15-Minute Averaged Wind Speed. 6

Table 4. Definitions of Time Periods Used in Describing Diurnal Variations. 7

Table 5. Months Used in Describing Seasonal Variations. 7

Table 6. Tukey Grouping Showing the Significance of Monthly Mean Differences of Mean Wind Speed over the Five-Year Period. 9

Table 7. Tukey Grouping Showing the Significance of Monthly Mean Differences of Peak Wind Gust over the Five-Year Period. 10

Table 8. Tukey Grouping Showing the Significance of Monthly Mean Differences of $\sigma_{\mathrm{E}}$ over the Five-Year Period. 10

Table 9. Tukey Grouping Showing the Significance of Monthly Mean Differences of $\sigma_{\mathrm{A}}$ over the Five-Year Period. 11

Table 10. Tukey Grouping Showing the Significance of Monthly Mean Differences of Solar Radiation over the Five-Year Period. 11

Table 11. Statistical Summary of the Froude Number and Brunt-Vaisala Frequency by Time-of-day for the Five-Year Period 1995-99. 16

Table 12. Estimates of the fraction of kinetic energy provided by forced ventilation 50-300 $\mathrm{cfm}$ to the energy of a recirculating eddy in a simple cubical block-shaped building. 22 


\section{Wind Conditions and Flow around Windbreaks at SRS}

\section{Executive Summary and Recommendations}

A study was funded by High Level Waste Management to determine the effect of increasing the wind speed threshold for High-Level Waste projects using windbreaks. It was also requested to determine the conditions enabling particles to be transported up and over a windbreak and to include the effect of forced ventilation up to 300 $\mathrm{cfm}$.

The Atmospheric Technologies Group's Wind System database for the Central Climatology Station was used to determine the effect of a wind threshold change. Journal articles and reports on wind tunnel and towing tank studies, theoretical studies of fluid mechanics, and numerical simulations were used to help predict wind flow and dispersion around windbreaks in the High Level Waste Tank Farm.

Changing the criterion for a high potential job from $10 \mathrm{mph}$ to $20 \mathrm{mph}$ will increase the percentage of time that jobs can be performed. If the wind criterion is based on the peak gust there will be a gain in percentage of time that jobs can be performed from $67 \%$ to $96 \%$. If the wind criterion is based on the 15 -minute averaged winds however, the gain is only from $96.6 \%$ to $99.9 \%$. If the wind criterion is based on changing the peak gust to $14 \mathrm{mph}$ there will be a gain in percentage of time that jobs can be performed from $67 \%$ to $85 \%$.

On the average, the highest wind speeds occur in the afternoon; about double those of the late evening, around midnight, and before sunrise. The 15-minute averaged wind speeds in the morning after sunrise and in the early evening (late afternoon) are about $40 \%$ higher than in the non-daytime hours and about $15 \%$ below midday winds.

The measured Froude number distribution based on the gravel berm height in non-daytime hours in H-Area near the High Level Waste (HLW) tanks is more frequently indicative of neutral conditions. This means the wind flow most often tends to go over the large gravel berm near the HLW tanks rather than flowing around the sides of the berm.

An increase in the wind speed will increase the kinetic energy of the mean flow and turbulence kinetic energy around a windbreak but the basic flow pattern dimensions will not change.

A wind speed increase around an open-topped windbreak will increase turbulent and kinetic energy which can result in a greater likelihood of particle resuspension. At a height to depth ratio 1/1, for example, a windbreak $10 \mathrm{ft}$ tall and $10 \mathrm{ft}$ deep (in the direction of the wind flow) there is a single recirculating eddy within a block-shaped, roofless windbreak and material can be easily transported out. At the height to depth ratios of $2 / 1$ and $4 / 1$ there are two stacked, recirculating eddies within the windbreak and material can still be transported out, but not so well as for the $1 / 1$ case. It appears that the 2/1 and 4/1 shaped windbreaks are safer from a particle resuspension point of view.

A ventilation system with flow in the range 50-300 cfm can significantly change the normal driven flow inside a simple (10ft)x(10ft)x(10ft) block-shaped windbreak.

Resuspension can also be aided by ventilation or forced circulation within the structure, especially if the forced circulation creates an eddy that can link up with cavity zones in the rear or on the roof (if one is present) of the windbreak. Resuspension can also be aided by creating an unstable temperature gradient within the windbreak.

\section{Recommendations:}

(1) At the present time there appears to be no compelling reason for not raising the upper limit for maximum wind speed gusts when working inside windbreaks from $10 \mathrm{mph}$ to $14 \mathrm{mph}$. Raising the limit to $14 \mathrm{mph}$ would enable $85 \%$ of the times available as opposed to $67 \%$ under the current limit of $10 \mathrm{mph}$ maximum gusts (measured at the surface).

(2) Further study of the windflow patterns is needed primarily to determine the circulation inside a windbreak, especially for a height to depth ratio of $1.5 / 1$. 


\section{Statistical Studies}

The Atmospheric Technologies Group was asked to determine the effect of increasing the wind speed threshold for High-Level Waste projects using windbreaks. The projects of concern are those with high potential for contamination while performing radiation protection procedures. The specific interest was the effect of increasing the wind speed from $10 \mathrm{mph}$ to various higher levels (in steps of $2 \mathrm{mph}$ ) for high potential jobs (and, as a consequence, from $12 \mathrm{mph}$ for low potential jobs). In order to accomplish this task, a statistical analysis of archived meteorological data was initiated. Five years of meteorological data were extracted from the lower levels (2 and 4-meters) of the Central Climatology Tower's data archives. The extracted data consisted of wind speed and direction, air temperature, dew point, horizontal and vertical turbulence intensities $\left(\sigma_{\mathrm{A}}\right.$ and $\sigma_{\mathrm{E}}$ ), peak wind gust, solar radiation, and rain amounts. Both speed and peak gust data are available within the archives. The wind speed is a 15-minute time-average and the peak wind gust is the highest wind speed acquired by the data acquisition system during a particular 15-minute period. The rainfall amount is the total accumulated precipitation during a 15-minute period.

During the data extraction process measures were taken to ensure high quality data. These measures included eliminating duplicate time records when the Weather Center computer powered down or lost power for some reason, and was brought back up during the same 15-minute period. The quality assurance measures also included eliminating values of temperature, dew point, wind speed and direction, turbulence intensities, and peak gust that were archived as exactly 0.0. Experience has shown that data elements that are exactly zero have a very high probability of being erroneous because of a non-functional instrument transmitting zero volts to the computer.

\section{A. Statistical Results Based on Maximum Wind Gusts}

The data set for maximum wind gusts is composed of 175,296 "observations", one for each of the fifteen-minute periods in the five-year time period. The number of missing observations in the time period is 4,644. The number of non-missing periods is 170,652 .

The distribution of wind gusts is shown as a vertical bar graph in Fig.1. Each bar represents a 2-mph speed range beginning at $0 \mathrm{mph}$, e.g., 0-2, 2-4, .. 34-36 mph. The size of vertical bars for peak gusts greater than the 35-mph midpoint become too small to read because of the vertical scaling so Fig. 2 was provided with a smaller scale to show these periods. Figure 2 covers the peak gust range from the 37-mph midpoint to the 99-mph midpoint (the highest gusts recorded in the five-year time span 1995-99).

The number of periods contained in the subset for high-potential wind periods based on the gust criterion being greater than $10 \mathrm{mph}$ is 56,970. The remainder of periods (less than the 10 -mph maximum gust speed) is 113,682 . Thus, about $33.4 \%$ (or about 1 in 3 
periods) of the periods could be considered high potential for contamination spread based on maximum wind gusts. Stated another way, $66.6 \%$ of the periods are available because the wind gusts are below the threshold.

Table 1 shows the benefit of increasing the wind limit on peak wind gust in increasing stages from 10-mph to 20-mph in steps of 2-mph. Increasing the peak wind gust from 10 -mph to 12 -mph adds 18,13115 -minute periods (10.6\%) for a total of $77.2 \%$.

(Increasing the peak wind gust from $10 \mathrm{mph}$ to $14 \mathrm{mph}$ adds 31,492 15-minute periods $(18.5 \%)$ for a total of $85.1 \%$. Increasing the peak wind gust from $10 \mathrm{mph}$ to $16 \mathrm{mph}$ adds 40,72115 -minute periods (23.9\%) for a total of $90.5 \%$. Increasing the peak wind gust from $10 \mathrm{mph}$ to $18 \mathrm{mph}$ adds 46,75415 -minute periods (27.4\%) for a total of $94 \%$. Increasing the peak wind gust from $10 \mathrm{mph}$ to $20 \mathrm{mph}$ adds 50,533 15-minute periods $(29.6 \%)$ for a total of $96.2 \%$.

Table 1.

Percentage Increase in the Number of Periods of 15-minute periods with Peak Wind Gusts in the Range Indicated Over Those at 10-mph

\begin{tabular}{|l|l|l|l|l|l|l|}
\hline Gust range & $\begin{array}{l}0-10- \\
\mathrm{mph}\end{array}$ & $\begin{array}{l}10-12- \\
\mathrm{mph}\end{array}$ & $\begin{array}{l}12-14- \\
\mathrm{mph}\end{array}$ & $\begin{array}{l}14-16- \\
\mathrm{mph}\end{array}$ & $\begin{array}{l}16-18- \\
\mathrm{mph}\end{array}$ & $\begin{array}{l}18-20- \\
\mathrm{mph}\end{array}$ \\
\hline $\begin{array}{l}\text { Additional } \\
\text { periods in } \\
\text { range }\end{array}$ & 0 & 18,131 & 13,361 & 9,229 & 6,033 & 3,779 \\
\hline $\begin{array}{l}\text { Total Periods } \\
\text { greater than } \\
\text { 10-mph }\end{array}$ & 0 & 18,131 & 31,492 & 40,721 & 46,754 & 50,533 \\
\hline $\begin{array}{l}\text { \% Increase in } \\
\text { Periods over } \\
\text { 10-mph } \\
\text { (Grand total } \\
\text { of periods is } \\
\text { 170,652) }\end{array}$ & 0.0 & 10.6 & 18.5 & 23.9 & 27.4 & 29.6 \\
\hline $\begin{array}{l}\text { \% Available } \\
\text { Periods Based } \\
\text { on Max Gust }\end{array}$ & 66.6 & 77.2 & 85.1 & 90.5 & 94.0 & 96.2 \\
\hline
\end{tabular}

Fig. 3 shows the cumulative distribution function for the peak gusts. The increase in the number of periods from 10 to 12 -mph can be seen by comparing the bars at the midpoints for $9 \mathrm{mph}$ and $11 \mathrm{mph}$. Similar comparisons of the vertical bars show qualitatively the same information as contained in Table 1. 


\section{B. Statistical Results Based on 15-Minute-Averaged Wind Speeds}

The data set for the 15-minute-averaged wind speeds is also composed of 175,296 "observations", one for each of the fifteen-minute periods in the five-year time period. The number of missing observations in the remainder category is 4,741 . The total number of non-missing periods is 170,555 .

The distribution of 15-minute-averaged wind speeds is shown as a vertical bar graph in Fig. 4 (this time with a 1.0-mph speed range for the midpoints of each vertical bar). Since the number of periods for 15-minute-averaged wind speeds greater than the 20.5mph midpoint becomes too small to read because of the vertical scaling, Fig. 5 was provided with a smaller vertical scale to show these periods. Figure 5 covers the 15minute-averaged wind speeds from the 19-mph midpoint to the 79-mph midpoint (the highest 15-minute-averaged wind speeds recorded in the five-year time span 1995-99).

The number of periods contained in the subset for high-potential wind periods based on the 15-minute-averaged wind speeds being greater than $10 \mathrm{mph}$ is only 5,859 . The remainder (less than the 10-mph averaged speed) is 164,696 . Thus only $3.44 \%$ (or about 1 in 30 periods) of the observations can be considered high potential for contamination spread based on 15-minute-averaged wind speeds. Stated another way, $96.56 \%$ of the periods are available because the wind gusts are below the threshold.

Table 2 shows the benefit of increasing the wind speed limit in increasing stages from $10-\mathrm{mph}$ to 20 -mph in steps of 2-mph. Increasing the 15-minute-averaged wind speeds from $10 \mathrm{mph}$ to $12 \mathrm{mph}$ adds 3,536 15-minute periods (2.07\%) for a total of $98.63 \%$. Increasing the 15-minute-averaged wind speeds from $10 \mathrm{mph}$ to $14 \mathrm{mph}$ adds 1,52615 minute periods $(2.96 \%)$ for a total of $99.52 \%$. Increasing the 15 -minute-averaged wind speeds from $10 \mathrm{mph}$ to $16 \mathrm{mph}$ adds 5,622 15-minute periods (3.30\%) for a total of $99.86 \%$. Increasing the 15 -minute-averaged wind speeds from $10 \mathrm{mph}$ to $18 \mathrm{mph}$ adds 5,79315 -minute periods $(3.40 \%)$ for a total of $99.96 \%$. Increasing the 15 -minute-averaged wind speeds from $10 \mathrm{mph}$ to $20 \mathrm{mph}$ adds 5,837 15-minute periods (3.42\%) for a total of $99.98 \%$. 
Table 2.

Percentage Increase in the Number of Periods of 15-minute periods with 15-MinuteAveraged Wind Speeds Less Than the Speed Indicated Over Those at 10-mph

\begin{tabular}{|l|l|l|l|l|l|l|}
\hline $\begin{array}{l}\text { Speed } \\
\text { range }\end{array}$ & $\begin{array}{l}0-10- \\
\mathrm{mph}\end{array}$ & $\begin{array}{l}10-12- \\
\mathrm{mph}\end{array}$ & $\begin{array}{l}12-14- \\
\mathrm{mph}\end{array}$ & $\begin{array}{l}14-16- \\
\mathrm{mph}\end{array}$ & $\begin{array}{l}16-18- \\
\mathrm{mph}\end{array}$ & $\begin{array}{l}18-20- \\
\mathrm{mph}\end{array}$ \\
\hline $\begin{array}{l}\text { Additional } \\
\text { periods in } \\
\text { range }\end{array}$ & 0 & 3,536 & 1,526 & 560 & 171 & 44 \\
\hline $\begin{array}{l}\text { Total } \\
\text { Periods } \\
\text { greater } \\
\text { than 10- } \\
\text { mph }\end{array}$ & 0 & 3,536 & 5,062 & 5,622 & 5,793 & 5,837 \\
\hline $\begin{array}{l}\text { \% Increase } \\
\text { in Periods } \\
\text { over 10- } \\
\text { mph } \\
\text { (Grand } \\
\text { total of } \\
\text { periods is } \\
\text { 170,555) }\end{array}$ & 0.0 & 2.07 & 2.96 & 3.30 & 3.40 & 3.42 \\
\hline $\begin{array}{l}\text { \% } \\
\text { Available } \\
\text { Periods } \\
\text { Based on } \\
\text { Ave. Wind }\end{array}$ & 96.56 & 98.63 & 99.52 & 99.86 & 99.96 & 99.98 \\
\hline
\end{tabular}

Fig. 6 shows the cumulative distribution function for the 15-minute-averaged wind speeds. The increase in the number of periods from 10 to $11-\mathrm{mph}(2.07 \%)$ can be seen by examining the percentage increase from the midpoint at $9.5 \mathrm{mph}$ to the midpoint at 11.5 $\mathrm{mph}$. Similar comparisons show qualitatively the same information as contained in Table 2.

\section{Correlation of 15-min-Averaged Wind Speeds and Peak Wind Gusts}

The 15-minute-averaged wind speeds and the peak wind gusts are related to one another. A measure of this relationship can be expressed by the Pearson correlation coefficient which is 0.96 between the two variables. The mean value of the 15 -minute averaged speed over all the periods is $4.29 \mathrm{mph}$ with a standard deviation of $2.64 \mathrm{mph}$, and the mean value of the peak gust is $8.44 \mathrm{mph}$ with a standard deviation of $5.67 \mathrm{mph}$. 
By using the 15-min-averaged wind speed as the independent variable in a regression analysis, one can obtain a regression equation of the form

Gust $(\mathrm{mph})=2.027^{*}$ Fifteen-Minute-Averaged Speed $(\mathrm{mph})-0.267(\mathrm{mph})$.

The standard error of the intercept is $0.0071 \mathrm{mph}$ and the standard error of the slope is 0.0014. In a simplified fashion this result might be called the "two times rule" since the coefficient of the speed term is almost exactly 2.0. This implies that the peak gust in a fifteen-minute period can be reliably estimated by multiplying the mean wind speed by a factor of two. This is a statistical relationship and there may be other factors that could influence the situation, one possibly being the time of day. If any 24-hr day is broken down into two periods - daytime and nighttime, corresponding to the presence or absence of sunlight (greater or less than 6 watts $/ \mathrm{m}^{* *}$ ) then the regression relationship slightly changed as is shown in Table 3 . The greatest change is in the intercept rather than the slope of the regression equation (from $+0.0819 \mathrm{mph}$ for daytime to $-0.3828 \mathrm{mph}$ for nighttime).

Table 3.

Regression Analysis Parameters by Daytime and Nighttime for Predicting the Peak Gust from the 15-Minute Averaged Wind Speed.

\begin{tabular}{|l|l|l|}
\hline Data Set & Slope & Intercept \\
\hline Complete 5-years & 2.0268 & -0.2669 \\
\hline $\begin{array}{l}\text { Daytime (Solar rad. }>6 . \\
\text { Watts } / \mathrm{m}^{* *} \text { ) }\end{array}$ & 1.9873 & +0.0819 \\
\hline $\begin{array}{l}\text { Nighttime (Solar rad. } \\
<=6 . \text { Watts } / \mathrm{m}^{* *} \text { 2) }\end{array}$ & 2.0220 & -0.3828 \\
\hline
\end{tabular}

It is also useful to know how the peak gust and 15-minute mean winds change during the course of the seasons and of the parts of a complete day. By taking advantage of the previous regression equation result, it is only necessary to provide results for one or the other of the two, peak gust or 15-minute mean speed, since they are statistically related. The seasonal breakdown for 15-minute mean speed is shown in Fig. 7. Wind speeds in the spring tend to be the highest while those in autumn are typically the lowest by about $20 \%$. The diurnal breakdown is shown in Fig. 8. The 24-hour day has been broken down into six periods as follows: pre-(sun)rise, post-(sun)rise, afternoon, early eve(ning), late eve(ning), and midnight. The definitions of these time periods are shown in Table 4 and the seasonal definitions are shown in Table 5. 
Table 4 .

Definitions of Time Periods Used in Describing Diurnal Variations

\begin{tabular}{|c|c|c|}
\hline Beginning Hour (EST) & Ending Hour (EST) & Designation \\
\hline 12 & 15 & Afternoon \\
\hline 16 & 19 & Early Even(ing) \\
\hline 20 & 23 & Late Even(ing) \\
\hline 0 & 3 & Midnight \\
\hline 4 & 7 & Pre-(sun)rise \\
\hline 8 & 11 & Post-(sun)rise \\
\hline
\end{tabular}

Table 5.

Months Used in Describing Seasonal Variations

\begin{tabular}{|c|c|c|}
\hline Beginning Month & Ending Month & Designation \\
\hline December & February & Winter \\
\hline March & May & Spring \\
\hline June & August & Summer \\
\hline September & November & Autumn \\
\hline
\end{tabular}

The highest wind speeds occur in the afternoon; about double those of the late evening, around midnight, and before sunrise. The 15-minute averaged wind speeds in the morning after sunrise and in the early evening (late afternoon) are about $40 \%$ higher than in the non-daytime hours and about $15 \%$ below midday winds. It should be borne in mind that even though these are average conditions; they should prove useful for planning purposes.

The complete breakdown by season and time of day is shown in Fig. 9. Note that relative speed changes among the time-of-day designations are preserved in the seasonal groupings as well. Thus, even though mean summer wind speeds are lower than those in the spring, the overall diurnal cycle (with afternoon speeds higher than nighttime) is preserved.

\section{Changes of Statistics of 15-Minute Mean Wind, Peak Gust, $\sigma_{\mathrm{A}}$ and $\sigma_{\mathrm{E}}$ with Time}

The five-year database affords an opportunity to determine if the 15-minute mean speeds, peak gusts, and turbulence intensities have trends (changes over the five-year database). To make this determination the entire 5-year record was examined and monthly averages for each of the four variables including, 15-minute-mean wind speed, peak gust, $\sigma_{\mathrm{A}}$ and $\sigma_{\mathrm{E}}$, were compiled. A statistical test was then set up to answer the question as to whether any of these monthly means for the five years were statistically different over the five-year time period at the $5 \%$ significance level. This means that 
there is only a 1 in 20 chance that real differences among the monthly means over the five year period will escape detection.

The results are shown in Tables 6-9 by means of a statistical indicator known as the Tukey grouping. When the Tukey grouping letter (of the alphabet) repeats itself, as it does in the left-hand column of Table 6, the year-to-year differences are not statistically significant. When the Tukey grouping letter changes, a statistically significant difference has been detected (as it does in the left-hand column of Table 8). For those years where the Tukey grouping letter overlaps, it is not possible to differentiate the year as belonging to one group or the other, rather it can be said that the year where the overlap occurs fits equally well into either of the two groups. 
Table 6 .

Tukey Grouping Showing the Significance of Monthly Mean Differences of Mean Wind speed over the Five-Year Period

Variable: Monthly averaged 15-minute mean speed

Alpha $=0.0 \overline{5}$, degrees of freedom $=55$, mean square error $=0.41$

Critical Value of Studentized Range $=3.989$

Minimum Significant Difference $=0.7414$

Means with the same letter are not significantly different.

$\begin{array}{crrr}\text { Tukey Grouping } & \text { Mean } & \text { N } & \text { YR } \\ \text { A } & 4.4988 & 12 & 1996 \\ \text { A } & 4.2917 & 12 & 1995 \\ \text { A } & & & \\ \text { A } & 4.2502 & 12 & 1997 \\ \text { A } & 4.2175 & 12 & 1998 \\ \text { A } & 4.1902 & 12 & 1999 \\ \text { A } & & & \\ \text { A } & 4909 \\ \text { A } & 4 & & \end{array}$




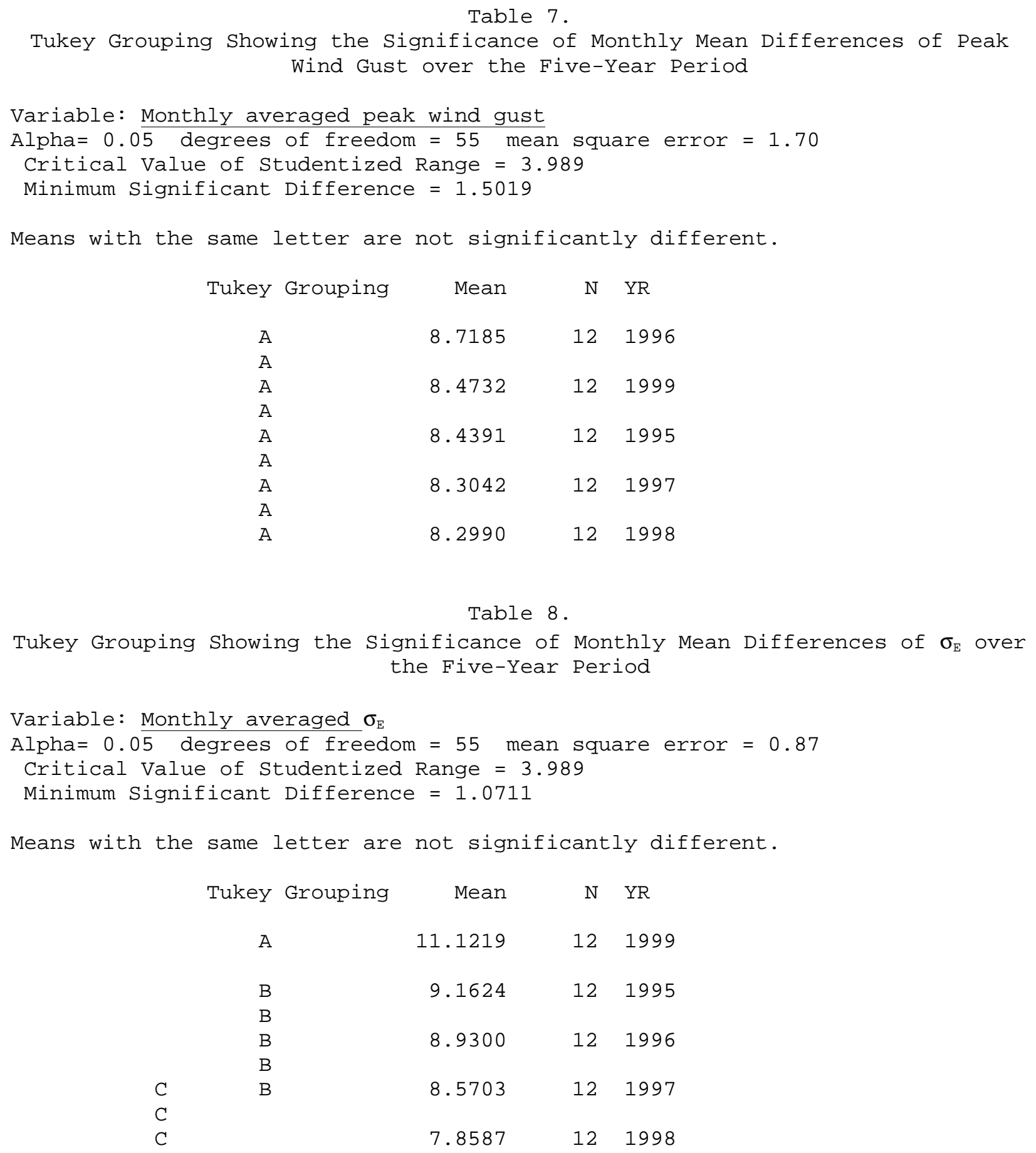


Table 9 .

Tukey Grouping Showing the Significance of Monthly Mean Differences of $\sigma_{\mathrm{A}}$ over the Five-Year Period

Variable: Monthly averaged $\sigma_{A}$

Alpha $=0.05$ degrees of freedom $=55$ mean square error $=3.79$

Critical Value of Studentized Range $=3.989$

Minimum Significant Difference $=2.2402$

Means with the same letter are not significantly different.

$\begin{array}{crrr}\text { Tukey Grouping } & \text { Mean } & \text { N } & \text { YR } \\ \text { A } & 25.7349 & 12 & 1997 \\ \text { A } & & & \\ \text { A } & 25.6357 & 12 & 1999 \\ \text { A } & & & \\ \text { A } & 25.5841 & 12 & 1995 \\ \text { A } & 25.5344 & 12 & 1998 \\ \text { A } & & & \\ \text { A } & 25.1507 & 12 & 1996 \\ \text { A } & & & \end{array}$

Table 10 .

Tukey Grouping Showing the Significance of Monthly Mean Differences of Solar Radiation over the Five-Year Period

Variable: Monthly averaged solar radiation

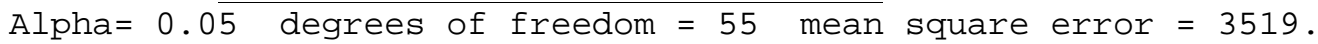

Critical Value of Studentized Range $=3.989$

Minimum Significant Difference $=68.299$

Means with the same letter are not significantly different.

Tukey Grouping

Mean N YR

$\begin{array}{llll}\mathrm{A} & 189.71 & 12 & 1998 \\ \mathrm{~A} & & & \\ \mathrm{~A} & 188.12 & 12 & 1999 \\ \mathrm{~A} & & & \\ \mathrm{~A} & 186.56 & 12 & 1996 \\ \mathrm{~A} & & & \\ \mathrm{~A} & 182.71 & 12 & 1997 \\ \mathrm{~A} & & & \\ \mathrm{~A} & 177.23 & 12 & 1995\end{array}$


Tables 6, 7, 9, and 10 show no statistically significant differences among the variables for mean speed, peak wind gust, $\sigma_{\mathrm{A}}$, and solar radiation over the five-year time period.

Table 8 , on the other hand, does show some statistically significant differences for $\sigma_{\mathrm{E}}$. The turbulence intensity $\sigma_{\mathrm{E}}$ is strongly affected by heat convection and surface roughness. An increase in the mean temperature over the five-year period could produce changes in the vertical turbulence intensity $\sigma_{\mathrm{E}}$. However, upon closer examination, the 1999-value of $\sigma_{\mathrm{E}}$ shows the highest value, whereas 1998 -value is lowest. So one cannot conclude that there is an increasing upward trend in the value of $\sigma_{\mathrm{E}}$ due to increasing temperature. Undoubtedly, there are other reasons that the vertical component of turbulence intensity shows statistically significant changes over the fiveyear time period. Most likely, changes in the configuration of flow obstacles in various upwind directions (fetch) around the CC Tower are the most direct cause of changes in $\sigma_{\mathrm{E}}$ rather than temperature changes (Parker, 2000).

\section{E. Approximate Statistical Model for the Distribution of 15-minute Averaged Speeds for the 5-year Period}

Knowing if an empirical statistical distribution such as for the 15-minute mean speed fits into one of the standard statistical models is useful since it enables one to use known properties of the standard model to make statistical predictions and compute confidence intervals. The SAS ${ }^{\circledR}$ statistical software enables the empirical distribution of 15-minute averaged speeds for the 5-year period to be tested for the best fit of analytical statistical model among several standard statistical models. Based on the overall shape of the empirical distribution, two distributions were tested including the Weibull and the exponential distributions. The results showed that the empirical distribution was fairly close to a Weibull distribution with a mean of $4.3 \mathrm{mph}$, a scale of 4.82 , and a shape parameter of 1.71. This distribution is quite common in describing the wind distributions, for example, the Weibull distribution is used in computing the electrical power that can be generated with wind turbines. The mathematical form of the Weibull distribution is

$F(t)=1-\exp \left[-(t / b)^{k}\right], t>0$,

where $\mathrm{k}$ is the shape parameter, $\mathrm{b}$ is the scale, and $\mathrm{t}$ is the independent random variable.

The mean wind speed or the scale parameter, $b$, is used to indicate how windy the site is, on average. The shape parameter, $k$, tells how peaked the distribution is, i.e. if the wind speeds always tend to be very close to a certain value, the distribution will have a high $\mathrm{k}$ value, and be very peaked. 


\section{Results from Previous Fluid Modeling Studies Having Relevance to Wind Flow and Dispersion Around Terrain Obstacles and Windbreaks at the High Level Waste Tank Farm}

There are a number of scientific papers in journals and technical reports on fluid modeling studies that have relevance to wind flow and dispersion around windbreaks in the High Level Waste Tank Farm. Important contributions have come from simulations in wind tunnels and towing tanks, theoretical studies of fluid mechanics, and numerical simulations of fluid flow.

\section{A. Requirements for Validity of Wind Tunnel Studies}

Wind tunnel studies are required to meet certain "similarity" (Plate, 1982) criteria before a modeler can be confident that the wind tunnel results transfer to the atmospheric boundary layer or "prototype". These similarity criteria include scaling the model so that it is geometrically similar and enforcing dynamic similitude. Dynamic similitude requires similarity between the non-dimensional parameters as follows: Rossby number,

$$
\mathrm{Ro}=\mathrm{V}_{\mathrm{R}} / \mathrm{L}_{\mathrm{R}} \mathrm{f}
$$

where $V_{R}$ is a reference velocity, $L_{R}$ is a reference length, and $\mathrm{f}$ is the Coriolis parameter; Reynolds number,

$$
\operatorname{Re}=\mathrm{V}_{\mathrm{R}} \mathrm{L}_{\mathrm{R}} / \mathrm{v},
$$

where $v$ is the kinematic viscosity;

Strouhal number,

where $t_{R}$ is the reference time;

$$
\text { St }=\left(\mathrm{V}_{\mathrm{R}} / \mathrm{L}_{\mathrm{R}}\right) \mathrm{t}_{\mathrm{R}^{\prime}}
$$

densimetric Froude number,

$$
\mathrm{Fr}=\mathrm{V}_{\mathrm{R}} / \sqrt{L_{R} g},
$$

where $g^{\prime}=g \Delta T_{R} / T_{R}$ and $T_{R}$ is a reference temperature and $g$ is the acceleration of gravity;

the Eckert number,

$$
\mathrm{Ec}=\rho\left(\mathrm{V}_{\mathrm{R}}\right)^{2} / \mathrm{c}_{\mathrm{p}} \Delta \mathrm{T}_{\mathrm{R}}
$$

where $c_{p}$ is the specific heat of air at constant pressure;

and Prandtl number,

$$
\operatorname{Pr}=\rho \vee c_{p} / k
$$

where $\mathrm{k}$ is the thermal conductivity and $\rho$ is the density of air.

Strictly speaking, all of these numbers should be the same between the model and the prototype. The initial and boundary conditions between the model and the prototype should scale the same as well. 
For any practical simulation it is impossible to attain exact similarity for all these parameters. Fortunately, it is often possible to relax a few of the conditions, for example, the Eckert number does not have any dynamic significance so it is often ignored, and the Strouhal number can be neglected for steady flow. The Prandtl number is the same as long as the fluid is air, so that leaves the Rossby, Reynolds, and Froude numbers to deal with. Of these the Froude number is important for non-neutral flows and the Rossby number must be considered whenever the distance scales are long enough (usually several kilometers) so that the Coriolis force becomes important (Plate, 1982).

Since typical Reynolds numbers in the atmosphere are huge, exact Reynolds number similarity is impossible to attain as well. However, it is often possible to invoke a condition called Reynolds number independence, which means that once the Reynolds number in the laboratory becomes sufficiently high enough for turbulent flow to be maintained, it need not be increased further. In this condition, the overall flow structure will be similar, although there may be differences in the smaller scales of motion. Thus, it is not necessary to exactly match the Reynolds numbers found in the atmospheric boundary layer. A good discussion on Reynolds number independence is contained in Snyder (1981).

A follow-up paper by Snyder (1992) on Reynolds number independence established that the Reynolds number had to exceed 11,000 in order to obtain Reynolds number independence for model simulations in a salt-water stratified tank.

\section{B. Flow Patterns over a Three-Dimensional Hill in a Stratified Fluid}

One useful, important result comes from a towing tank experiment carried out by Hunt, Snyder, and Lawson, (1978). This experiment simulated flow over three-dimensional hills in a stratified fluid. The relevant parameter in characterizing the flow is the Froude number (above), the dimensionless combination representing the ratio of inertial forces to gravitational forces in the Navier-Stokes equations. The Froude number is $\mathrm{U} / \mathrm{Nh}$ where $\mathrm{U}$ is the mean speed, $\mathrm{h}$ is a characteristic height of the hill, and $\mathrm{N}$ is the BruntVaisala frequency. The Brunt-Vaisala frequency is the frequency of oscillation of an air parcel in a stably stratified fluid and is given by $\sqrt{g \partial \rho / \rho_{0} \partial z}$. Hunt, Snyder, and Lawson, interpreted the results of the experiments in terms of the size of the Froude number (based on the hill height).

Large Froude numbers imply that momentum effects outweigh gravitational effects thus the streamlines should flow up and over hills rather than around them. As the thermal stratification of the fluid increases and $F$ drops below a value of one, the fluid tries to move around the hill rather than up and over. Hunt and Snyder (1980) investigated this phenomenon and came up with the concept of a dividing streamline. The dividing streamline is defined as the streamline at the height $\mathrm{H}_{\mathrm{s}}=\mathrm{h}(1-\mathrm{F})$, where $\mathrm{h}$ is the height of the hill, and F is the Froude number (where F $<1$, of course). If an 
upwind plume height is smaller than this dividing streamline height, it will impact the hill surface; otherwise, it will go over the top of the hill.

In another important investigation Snyder (1992) showed that the concentration fields in building wakes were independent of Froude number, provided the Froude number was greater than 2.5 .

It is useful to gain a better feeling about the natural variation of the Froude number based on a hill height of about $7.5 \mathrm{~m}$, which is the height of the gravel berm in the High Level Waste Tank area. Fig. 10 shows the distribution based on the berm height and the meteorological measurements from the period 1995-99. The density derivative in the Froude number definition was estimated using temperature and dew point measurements at 2 and 18 meters and the wind speeds at 4 meters on the CC tower. The predominate part of the distribution favors near neutral conditions, meaning that the flow tends to go over the hill rather than around it. The distribution by season and time of day is shown in Fig. 11. The mean value and standard deviations of the Froude number and the Brunt Vaisala frequency for different times of day are show in Table 11. 
Table 11 .

Statistical Summary of the Froude Number and Brunt-Vaisala Frequency by Timeof-day for the Five-Year Period 1995-99.

TIME_DAY=AFTERNOON

\begin{tabular}{|c|c|c|c|c|c|}
\hline Variable & $\mathrm{N}$ & Mean & Std Dev & Minimum & Maximum \\
\hline FROUDE & 2318 & 10.0289903 & 6.5831410 & 1.0681849 & 41.9653700 \\
\hline BRUNT & 2335 & 0.0414851 & 0.0231355 & 0.0178987 & 0.2210482 \\
\hline
\end{tabular}

TIME_DAY=EARLY_EVE

\begin{tabular}{|c|c|c|c|c|c|}
\hline Variable & $\mathrm{N}$ & Mean & Std Dev & Minimum & Maximum \\
\hline $\mathrm{FRC}$ & 11373 & 7.2518778 & 6.6408173 & 0.1448567 & 64.64 \\
\hline BRUNT & 11424 & 0.0417076 & 0.0210862 & 0.0179474 & 0.1722920 \\
\hline
\end{tabular}

TIME_DAY=LATE_EVE

\begin{tabular}{|c|c|c|c|c|c|}
\hline Variable & $\mathrm{N}$ & Mean & Std Dev & Minimum & Maximum \\
\hline ROUDE & 22225 & 5.5648734 & 5.6160469 & 0.0858916 & 51.8284907 \\
\hline RUNT & 22349 & 0.0495812 & 0.0248930 & 0.0179800 & 0.1716751 \\
\hline
\end{tabular}

TIME_DAY=MIDNIGHT

\begin{tabular}{|c|c|c|c|c|c|}
\hline Variable & $\mathrm{N}$ & Mean & Std Dev & Minimum & Maximum \\
\hline FROUDE & 21549 & 5.5999598 & 5.5897024 & 0.0624570 & 60.7242657 \\
\hline BRUNT & 21700 & 0.0450903 & 0.0223241 & 0.0180463 & 0.1713898 \\
\hline
\end{tabular}

TIME_DAY=POST_RISE

\begin{tabular}{|c|c|c|c|c|c|}
\hline Variable & $\mathrm{N}$ & Mean & Std Dev & Minimum & Maximum \\
\hline FROUDE & 4525 & 7.8409907 & 6.5051941 & 0.0931338 & 51.6747862 \\
\hline BRUNT & 4577 & 0.0411695 & 0.0232055 & 0.0180249 & 0.2235894 \\
\hline
\end{tabular}

TIME_DAY=PRE_RISE

\begin{tabular}{|c|c|c|c|c|c|}
\hline Variable & $\mathrm{N}$ & Mean & Std Dev & Minimum & Maximum \\
\hline FROUDE & 19357 & 5.5294359 & 5.2148948 & 0.0663845 & 50.7090480 \\
\hline BRUNT & 19521 & 0.0421430 & 0.0200178 & 0.0180974 & 0.1716326 \\
\hline
\end{tabular}




\section{Flow over Bluff Bodies Such as Windbreaks}

More often than not, the flow in the vicinity of the high-level waste tanks encounters small block-shaped structures or buildings (rectangular-parallelepiped-shaped obstacles). Some of these are temporarily constructed as windbreaks to prevent the spread of contamination and others are fixed small to medium-sized buildings used for various purposes. A sizeable fraction of the windbreaks are constructed without a roof or with an opening in the roof to allow access by a crane or similar equipment.

Hosker (1984) uses the term "bluff bodies" to refer to all these types of flow obstacles. Hosker also provided some extremely useful flow diagrams showing streamline patterns around a bluff body exposed to a steady wind. One of these is repeated as Fig. 12 below. There are several points worth mentioning about Fig. 12. There are both (1) a highly turbulent cavity zone on the downwind side of the body and (2) a horseshoe vortex that wraps around the lower front and lateral sides of the body. The open end of the horseshoe bounds the cavity zone and extends further downwind. There are also (3) regions of separated floor on the roof, front, and sides of the body where recirculation and turbulence can occur.

Within the cavity, horseshoe vortex, and recirculation zones there are areas of relatively high turbulence intensity, so micron-sized particles on surfaces can become resuspended rather easily if they are present. The particles could originate from the outer walls of the building (or bluff body), the adjacent ground surface, and the roof if one is present. If the roof is not present, particles from within the windbreak could become entrained into the ambient flow by means of a recirculating eddy inside the structure. Once small particles of micron size are resuspended by these mechanisms they can be easily transported downwind for considerable distances.

The following sections will address the flow around bluff bodies more specifically and give formulas for determining the dimensions of the cavity zones of windbreaks used at the Savannah River Site by Radiation Protection.

\section{Formulas for Determining Cavity Dimensions behind a Building}

All windbreaks and bluff bodies that are likely to be encountered in the High Level Waste tank farm will have a rear cavity zone that extends in the downwind direction. Hosker (1984) has provided several useful formulae for determining cavity dimensions.

In the limit when the body length $\mathrm{L}$ and width $\mathrm{W}$ both approach zero (Fig. 12), the cavity should disappear. For very wide and shallow depth bodies (large $\mathrm{W} / \mathrm{H}$, where $\mathrm{H}$ is the height, and small $\mathrm{L} / \mathrm{H}$ ) the results should approach formulas used for a twodimensional fence. For large $\mathrm{W} / \mathrm{H}$ and $\mathrm{L} / \mathrm{H}$ the cavity expressions should approach the data on two-dimensional rear-facing steps. 
Hosker developed the following equation to fit most of the data for short, block-type buildings. The parameter $X_{r}$ is the cavity length measured from the upwind building face.

$\mathrm{X}_{\mathrm{r}} / \mathrm{H}=\frac{L}{H}+\frac{A(W / H)}{(1.0+B W / H)}$ where A and B are weak functions of $\mathrm{L} / \mathrm{H}$ as in

$\mathrm{A}=-2.0+3.7(L / H)^{-1 / 3}$ and $\mathrm{B}=-0.15+0.305(L / H)^{-1 / 3}$.

For $\mathrm{L} / \mathrm{H} \geq 2$ (if the cavity extent is measured from the lee building face) then use the expression

$\mathrm{X}_{\mathrm{r}} / \mathrm{H}=\frac{1.75(W / H)}{(1.0+0.25 W / H)}$

Hosker also developed expressions for the crosswind extent of the cavity that can be expressed in terms of the maximum half-width $Y_{r}$ of the cavity. For short buildings the expression is

$2 \mathrm{Y}_{\mathrm{r}} / \mathrm{W}=1.1+1.7 \exp (-0.55 \mathrm{~W} / H)$

The location of the maximum crosswind extent of the wake cavity $X_{\mathrm{My}}$ is

$\mathrm{X}_{\mathrm{My}} / \mathrm{W}=0.3+2.0 \exp (-0.55 \mathrm{~W} / \mathrm{H})$.

Lastly, the maximum height $Z_{\mathrm{r}}$ of the recirculation zone of the cavity is given by

$\mathrm{Z}_{\mathrm{r}} / \mathrm{W}=1.0+1.6 \exp (-1.3 L / H)$.

Note that none of these formulae depend on the wind speed. This is an extremely important and useful result. The flow patterns will be the same size no matter if the wind is blowing at barely perceptible speeds or at $25 \mathrm{mph}$ or greater. Thus, raising the wind speed limit for radiation protection purposes will not dramatically change the dispersion patterns downwind of a windbreak built to contain radioactive particles. $A n$ increase in the (steady) wind speed can increase the kinetic energy of the mean flow and turbulence kinetic energy around the windbreak but the basic flow pattern dimensions will not change. 


\section{E. Wind Tunnel Simulations of Block-Building Shapes and Verification of Hosker's Results}

Snyder and Lawson (1996) performed wind tunnel investigations of simple blockshaped buildings and provided useful information on windbreaks that can be used at SRS. Figure 13 shows Snyder and Lawson's mean streamline patterns for a rectangular bluff body where the crosswind width (W) of the body is varied. Fig. 13 shows an upstream stagnation point, separation and reattachment streamlines, and the cavity zone. As the width of the body is increased the cavity size increases. The location of the stagnation point on the upwind face of the body is at a fairly constant height of approximately $2 \mathrm{H} / 3$. Note that the far upstream elevation of the stagnation streamline changes continuously from about $2 \mathrm{H} / 3$ for the cube to essentially ground level for the body with crosswind width of $10 \mathrm{H}$. The streamlines upstream of such bodies thus slope much more prominently upwards as the body width is increased. The horseshoe vortex is not recognizable upwind of the cube, but grows as the crosswind width of the body is increased. At $\mathrm{W}=10 \mathrm{H}$, its diameter appears to be about $\mathrm{H} / 2$.

These results have some valuable practical applications. Low plumes from sources located upwind of narrow windbreaks are likely to impinge directly on the upwind windbreak faces, and those from sources located upwind of wider windbreaks are much more likely to be lifted over the windbreak's top.

The streamlines separate from the upwind edge of the roof as shown in Fig. 13. For the cubical body, the separation streamline reattaches to the roof. This reattachment is followed immediately by a horizontal separation from the downwind roof edge, and the cavity height is about the same height as the body. For the wider bodies the cavity grows in height. The cavity height grows from about $\mathrm{H}$ for the cube to about $3 \mathrm{H} / 2$ for $\mathrm{W}=10 \mathrm{H}$. The widest body also has a secondary vortex at the downwind base. The length of the cavity (from the lee face of the body to the reattachment point) varies from $1.4 \mathrm{H}$ for the cube to $5.6 \mathrm{H}$ for $\mathrm{W}=10 \mathrm{H}$. These values agree fairly well (within about $10 \%$ ) with Hosker's (1984) equation for the cavity length where reattachment of the flow on the roof was observed (above).

Fig. 13 shows another an important point with regard to resuspension and dispersion from behind the body. Synder and Lawson (1996) showed that there is an attaching streamline (to the ground) in the lee of the body that originates in the cavity zone. Flow from the cavity spirals outward from a node in the cavity to the attachment point on the ground. This suggests an easy mechanism for particles to be transported out of the cavity zone and carried a few body heights downwind.

Fig. 14 shows the streamline patterns changes with the along-wind length $(\mathrm{L})$ of the body. The upstream patterns are independent of L. The cavity height attains a maximum of about $1.4 \mathrm{H}$ when $\mathrm{L}=0.015$ for the square flat plate. For the plate, reattachment on the roof cannot occur. When $\mathrm{L}=\mathrm{H} / 2$, the cavity height is reduced to 
about $1.15 \mathrm{H}$; for $\mathrm{L} \geq \mathrm{H}$, reattachment occurs on the roof, horizontal separation occurs at the downwind roof edge, and the cavity height is the same as the body height. The cavity length (measured from the rear building face) decreases from a value of $2.3 \mathrm{H}$ for the flat plate to $1.5 \mathrm{H}$ when $\mathrm{L}=\mathrm{H} / 2$. For $\mathrm{L} \geq \mathrm{H}$, the cavity length is nearly constant with a value of about $1.3 \mathrm{H}$. In the far wake of the short body, $(\mathrm{L}<\mathrm{H})$, the streamlines descend rapidly, but they are more nearly horizontal downwind of longer bodies.

Figure 15 shows how the streamline patterns change as the body height is varied. The elevation of the stagnation point on the upwind face of the body is about $2 \mathrm{H} / 3$ and remains constant. The streamlines upstream of about $1.5 \mathrm{~W}$ are essentially horizontal. The streamline pattern above the building is independent of body height; in all cases, the flow reattaches to the body roof, then separates again at the downwind edge of the roof. The cavity length is independent of the body height.

Snyder and Lawson also investigated the case of flow approaching the cube at 45 degrees (shown as the lower panel of Fig. 15). Their result was that the horseshoe vortex is less prominent and that downwash is much stronger in the wake. They also determined that this flow is dominated by the delta-wing-type vortices generated by the swept-back leading edges.

\section{F. Numerical Simulation Results for Block-Body Shapes with Open Roofs}

Numerical simulations of fluid flow have provided some useful results which help increase our understanding of the flow around an open roof windbreak in the atmospheric boundary layer. Of particular interest are simulations for driven cavity flow; so-called because the cavity is exposed to steady winds on the top that cause circulation within the cavity. The boundary conditions for numerical simulation of a driven cavity flow are shown in Fig. 16, with zero speed on the boundaries of the cavity everywhere except the top, where a constant speed is imposed. Fig. 17 shows the flow visualization scheme used by the FEATFLOW model. What is shown in Fig. 17 is the distribution of temperature in the air if the walls of the cavity (windbreak) were heated to a constant temperature and the air circulation transports this temperature. In many ways this flow visualization scheme can be thought of as giving the air a certain (constant) concentration of a substance and observing the spreading and circulation of the substance. The finite element FEATFLOW model originated in the University of Heidelberg from Dr. Stefan Turek, currently at Lehrstuhl III, Angewandte Mathematik und Numerik, Universität Dortmund, Germany.

Fig. 18 shows results from the FEATFLOW model for an open-roofed cavity whose height and depth are equal. The main feature of this flow depiction is a single recirculating vortex filling almost the entire cavity. Fig. 19 gives additional detail by using isolines of temperature (isotherms) to show the same flowfield as Fig. 18. 
A second simulation by Turek and his students shows how the flow changes if the cavity dimensions are changed so that the height to depth ratio is $2 / 1$. This numerical simulation is shown in Figs. 20 and 21. This time there are two distinct recirculating eddies instead of one; however, the lower eddy's circulation is obviously weaker than than the upper one. A third numerical simulation by the same group shows the circulation when the height to depth ratio is 4/1 shown in Figs. 22 and 23. Only two recirculating eddies have sufficient strength to be maintained in this case. The attempt to create additional recirculating eddies within the cavity below the first two has been thwarted by frictional effects on the cavity's inner surfaces and within the fluid itself.

Based on these results, it is highly likely that particles on the windbreak's inner walls, or those that are introduced from equipment into the recirculating eddy from equipment being worked on within the cavity, can be easily transported outside a windbreak with height to depth ratio (1/1), for example, a windbreak $10 \mathrm{ft}$ tall and $10 \mathrm{ft}$ deep (in the direction of the wind flow). This happens because the particles are carried from their origin on the equipment, floor, or walls inside the cavity to the top of the windbreak using the circulation and energy of the eddy inside. Once the particles are transported to the top of the enclosure they can exit the roof because of smaller eddies at the interface where wind is blowing across the top of the windbreak. After the particles exit the windbreak they are carried by the wind into the rear cavity zone and ultimately further downwind (provided they don't deposit on the ground within the rear cavity zone). In real flow situations (particularly in daytime convective conditions) the flow is intermittant (constantly spinning up, then spinning down and coming from different directions), which in turn cycles the turbulence intensity and aids vertical turbulent transport at the top of the windbreak.

At the height to depth ratios of $2 / 1$ and $4 / 1$ there are two recirculating eddies within the cavity and material can still be transported out, but not so well as for the $1 / 1$ case. It is highly tempting to conclude that the $2 / 1$ and $4 / 1$ shaped cavities are safer for particle resuspension unless other factors come into play.

Examples of other factors that might come into play are a heat source placed inside the cavity or an air ventilation system within the windbreak. It is difficult to speculate on the effect of a heat source since the position and strength of the source would have to be accurately specified before any results could be given. Provided that the position, distribution, and strength of the heat source were known, a numerical simulation could be run to dermine the circulation pattern. Undoubtedly, a strong heat source could upset the recirculating eddy(ies) and produce a chimney effect, where material is lifted from the bottom of the windbreak to the top by convective processes.

The effect of a ventilation system or some other forced, mechanical flow can be estimated in a qualitative fashion. For example, a 50-300 cfm source of ventilation would compare in terms of kinetic energy as shown in Table 12. 
Table 12. Estimates of the fraction of kinetic energy provided by forced ventilation 50$300 \mathrm{cfm}$ to the energy of a recirculating eddy in a simple cubical block-shaped building.

$\begin{array}{rrrrrrr}\text { Case } & \text { FLOW (cfm) } & \text { WIND (mph) } & \text { FLOW_CIR (Cfm) } & \text { FRACT } & \text { SIGNIF } & \text { N_SIG } \\ 1 & 50 & 1 & 17.046 & 2.9333 & \text { YES } & 1 \\ 2 & 50 & 5 & 85.228 & 0.5867 & \text { NO } & 1 \\ 3 & 50 & 10 & 170.455 & 0.2933 & \text { NO } & 1 \\ 4 & 50 & 12 & 204.546 & 0.2444 & \text { NO } & 1 \\ 5 & 50 & 14 & 238.637 & 0.2095 & \text { NO } & 1 \\ 6 & 50 & 16 & 272.728 & 0.1833 & \text { NO } & 1 \\ 7 & 100 & 1 & 17.046 & 5.8667 & \text { YES } & 2 \\ 8 & 100 & 5 & 85.228 & 1.1733 & \text { YES } & 3 \\ 9 & 100 & 10 & 170.455 & 0.5867 & \text { NO } & 3 \\ 10 & 100 & 12 & 204.546 & 0.4889 & \text { NO } & 3 \\ 11 & 100 & 14 & 238.637 & 0.4190 & \text { NO } & 3 \\ 12 & 100 & 16 & 272.728 & 0.3667 & \text { NO } & 3 \\ 13 & 150 & 1 & 17.046 & 8.8000 & \text { YES } & 4 \\ 14 & 150 & 5 & 85.228 & 1.7600 & \text { YES } & 5 \\ 15 & 150 & 10 & 170.455 & 0.8800 & \text { YES } & 6 \\ 16 & 150 & 12 & 204.546 & 0.7333 & \text { NO } & 6 \\ 17 & 150 & 14 & 238.637 & 0.6286 & \text { NO } & 6 \\ 18 & 150 & 16 & 272.728 & 0.5500 & \text { NO } & 6 \\ 19 & 200 & 1 & 17.046 & 11.7333 & \text { YES } & 7 \\ 20 & 200 & 5 & 85.228 & 2.3467 & \text { YES } & 8 \\ 21 & 200 & 10 & 170.455 & 1.1733 & \text { YES } & 9 \\ 22 & 200 & 12 & 204.546 & 0.9778 & \text { YES } & 10 \\ 23 & 200 & 14 & 238.637 & 0.8381 & \text { YES } & 11 \\ 24 & 200 & 16 & 272.728 & 0.7333 & \text { NO } & 11 \\ 25 & 250 & 1 & 17.046 & 14.6666 & \text { YES } & 12 \\ 26 & 250 & 5 & 85.228 & 2.9333 & \text { YES } & 13 \\ 27 & 250 & 10 & 170.455 & 1.4667 & \text { YES } & 14 \\ 28 & 250 & 12 & 204.546 & 1.2222 & \text { YES } & 15 \\ 29 & 250 & 14 & 238.637 & 1.0476 & \text { YES } & 16 \\ 30 & 250 & 16 & 272.728 & 0.9167 & \text { YES } & 17 \\ 31 & 300 & 1 & 17.046 & 17.6000 & \text { YES } & 18 \\ 32 & 300 & 5 & 85.228 & 3.5200 & \text { YES } & 19 \\ 33 & 300 & 10 & 170.455 & 1.7600 & \text { YES } & 20 \\ 34 & 300 & 12 & 204.546 & 1.4667 & \text { YES } & 21 \\ 35 & 300 & 14 & 238.637 & 1.2571 & \text { YES } & 22 \\ 36 & 300 & 16 & 272.728 & 1.1000 & \text { YES } & 23\end{array}$

The variables in Table 12 are defined as follows:

Case $=$ the case number,

FLOW $(\mathrm{cfm})=$ the flow rate of the ventilation within the windbreak in $\mathrm{cfm}$,

$\mathrm{WIND}(\mathrm{mph})=$ the wind speed at the roof of the windbreak,

FLOW_CIR $(\mathrm{cfm})=$ the flow rate of the recirculating eddy in the windbreak,

FRACT $=$ the ratio of FLOW to FLOW_CIR,

SIGNIF $=$ whether the ratio of FLOW (cfm) to FLOW_CIR exceeds 0.75 (an arbitrary criterion that indicates the ventilation's circulation has reached $75 \%$ of the unperturbed, recirculating eddy's circulation), 
and N_SIG = the number of significant cases.

The number of significant cases is 23 out of 36 or about $64 \%$. This means that nearly $2 / 3$ of the cases will be influenced by internal ventilation. The exact nature of this influence will depend on exactly how the ventilation is introduced into the windbreak. For example, if the outflow were to be directed upward near the upwind wall, the recirculating eddy would be strengthened. If the downwind wall were chosen instead, the recirculating eddy would be weakened or perhaps broken up into smaller scale turbulent eddies. Thus, the direction and position where the ventilation outflow are placed are crucial in determining the result.

\section{Conclusions}

(1) Changing the criterion for a high potential job from $10 \mathrm{mph}$ to a higher speed will increase the percentage of time that jobs can be performed. If the wind criterion is based on the peak gust there will be a gain in percentage of time that jobs can be performed of $10 \%$ to $30 \%$ (from a total of $66.6 \%$ of periods to $96.2 \%$ of periods).

(2) If the wind criterion is based on the 15-minute averaged winds however, the gain is only $2 \%$ to $3.5 \%$ (from a total of $96.56 \%$ of periods to $99.98 \%$ of periods).

(3) The peak gust in a 15-minute period can be reliably estimated from the 15-minute averaged winds by multiplying by a factor of two.

(4) On the average, the highest wind speeds occur in the afternoon; about double those of the late evening, around midnight, and before sunrise. The 15-minute averaged wind speeds in the morning after sunrise and in the early evening (late afternoon) are about $40 \%$ higher than in the non-daytime hours and about $15 \%$ below midday winds.

(5) There were no statistically significant differences among the variables for mean speed, peak wind gust, $\sigma_{\mathrm{A}}$, and solar radiation over the five-year time period.

(6) There were statistically significant differences for $\sigma_{\mathrm{E}^{\prime}}$ however the turbulence intensity $\sigma_{\mathrm{E}}$ was probably affected by changes in upwind flow obstacles.

(7) The distribution of 15-minute averaged winds was fairly close to a Weibull distribution with a mean of $4.3 \mathrm{mph}$, a scale of 4.82 , and a shape parameter of 1.71 .

(8) The measured Froude number distribution based on the gravel berm height in $\mathrm{H}-$ Area in non-daytime conditions near the High Level Waste Tanks is more frequently indicative of neutral conditions, meaning that the wind flow most often tends to go over the berm rather than around the sides.

(9) The dimensions of the rear wake cavity of a simple block-shaped windbreak can be computed from simple formulas given earlier in this report.

(10) An increase in the wind speed increases the kinetic energy of the mean flow and turbulence kinetic energy around a windbreak but the basic flow pattern dimensions do not change. 
(11) A wind speed increase around an open-topped windbreak will increase turbulent and kinetic energy which could result in a greater likelihood of particle resuspension.

(12) At a height to depth ratios $1 / 1$, for example, a windbreak $10 \mathrm{ft}$ tall and $10 \mathrm{ft}$ deep (in the direction of the wind flow) there is a single recirculating eddy within a blockshaped, roofless windbreak and material can be easily transported out. At the height to depth ratios of $2 / 1$ and $4 / 1$ there are two stacked, recirculating eddies within the cavity and material can still be transported out, but not so well as for the $1 / 1$ case. It appears that the $2 / 1$ and $4 / 1$ shaped cavities are safer from a particle resuspension point of view. Resuspension of particles from within a windbreak is aided by a height to depth ratio of $1 / 1$ since this ratio favors carrying particles from the floor of the windbreak to the roof by the internal recirculating eddy.

(13) A ventilation system with flow in the range $50-300 \mathrm{cfm}$ can significantly change the the normal driven flow inside a simple $(10 \mathrm{ft}) \times(10 \mathrm{ft}) \times(10 \mathrm{ft})$ block-shaped windbreak.

(14) Resuspension can also be aided by ventilation or forced circulation within the structure, especially if the forced circulation creates an eddy that can link up with cavity zones in the rear or on the roof (if one is present) of the windbreak.

Resuspension can also be aided by creating an unstable temperature gradient within the windbreak.

\section{References:}

Hosker, R. P., Jr., 1984: Flow and Diffusion Near Obstacles. Atmospheric Science and Power Production, DOE/TIC-27601, D. Randerson, Ed., Ch.7, 241-326. U.S. Dept. of Energy, Wash., DC.

Hunt, J. C. R., W. H. Snyder, and R. E. Lawson, Jr., 1978: Flow Structure and Turbulent Diffusion Around a Three-Dimensional Hill, Fluid Modeling Study on Effects of Stratification, Part 1. Flow Structure. EPA-600/4-78-041, July 1978, 84pp.

Hunt, J. C. R., and W. H. Snyder, 1980: Experiments on Stably and Neutrally Stratified Flow over a Model Three-Dimensional Hill, J. Fluid Mechl, 96(Pt. 4): 671-704.

Hunter, C. H. and C. O. Minyard, 1999: Estimating Wet Bulb Globe Temperature Using Standard Meteorological Measurements (U). WSRC-MS-99-00757.

Parker, M. J., 2000: Personal email.

Plate, E., 1982: Engineering Meteorology, Chapt. 13, 573-639. Elsevier Scientific Publishing Co., New York, NY, 740pp. 
Snyder, W. H., 1981: Guidline for Fluid Modeling of Atmospheric Diffusion, Environmental Sciences Research Laboratory, US EPA, RTP, NC, Report \# 600/8-81009, April 1981.

Snyder, W. H., 1992: Some Observations of the Influence of Stratification on Diffusion in Building Wakes, Invited presentation at the Institute of Mathematics and Its Applications Meeting on Stably Stratified Flows, Sept. 21-23, 1992, University of Surrey, Guildford, England.

Snyder, W. H. and R. E. Lawson, 1994: Wind-Tunnel Measurements of Flow Fields in the Vicinity of Buildings, $8^{\text {th }}$ Joint Conf. On Apps. Of Air Pollution Meteorology with A\&WMA, Nashville, TN, Jan. 23-28, 1994. 


\section{Central Climatology 4-Meter 1995-99 Peak Gust Distribution}

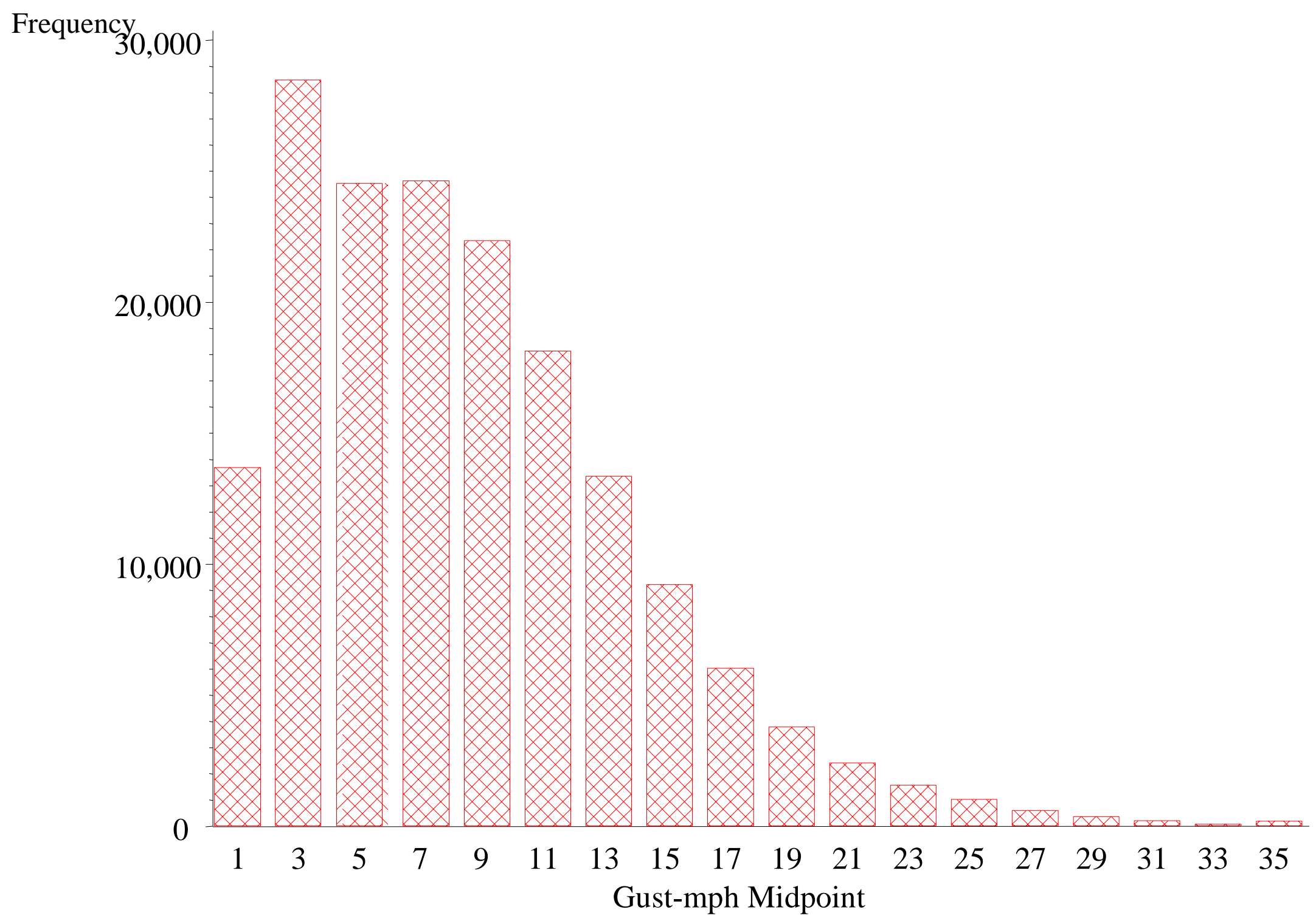

Figure 1. Distribution of Peak Gusts for Five Years (1995-99) from the Central Climatology 4-meter Level (1-35 mph) 


\section{Peak Gust Distribution 37-99 mph from the Central Climatology Station 4-meter \\ 40}

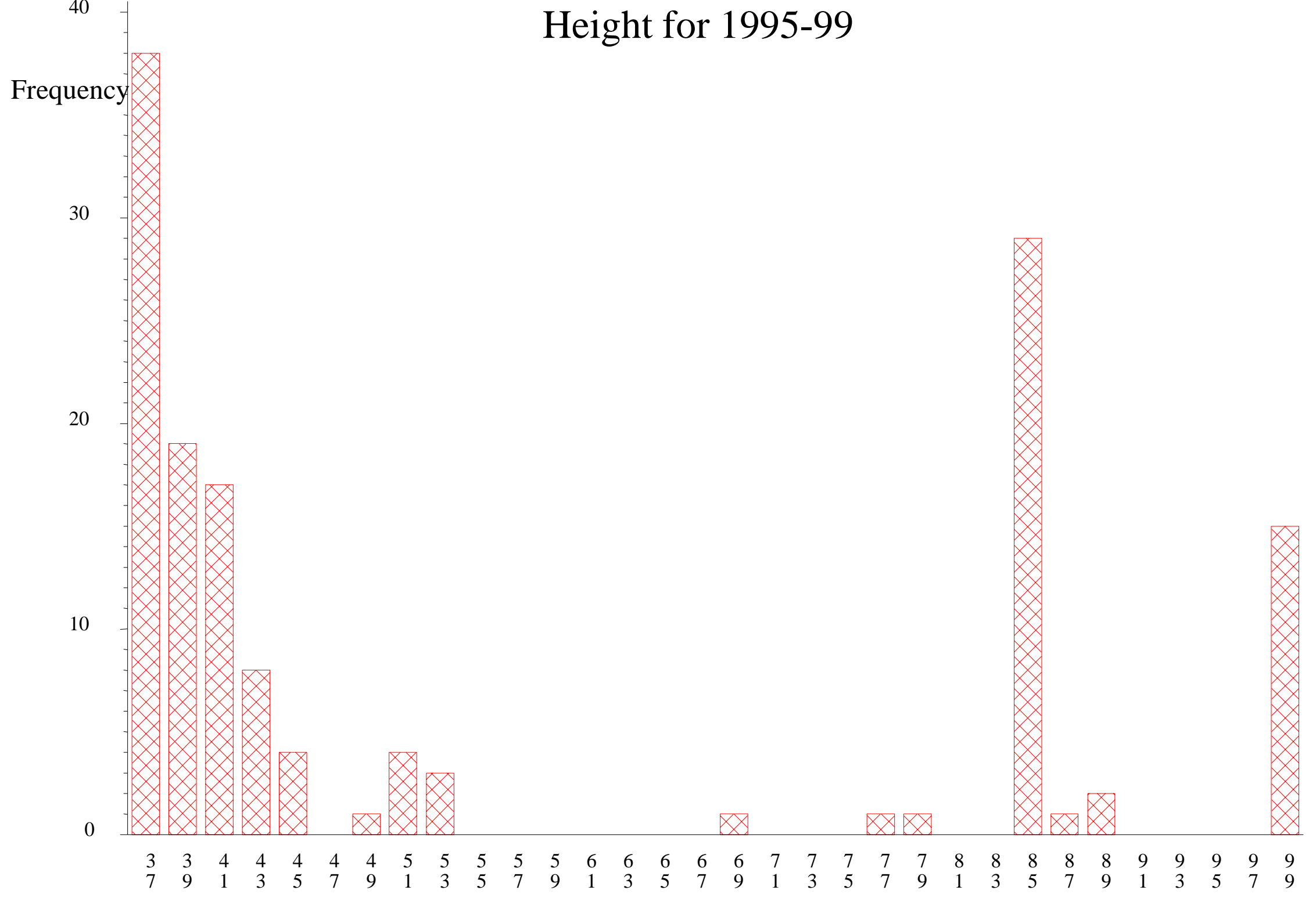

Gust-mph Midpoint

Figure 2. Distribution of Peak Gusts for Five Years (1995-99) from the Central Climatology 4-meter Level (37-99mph) 


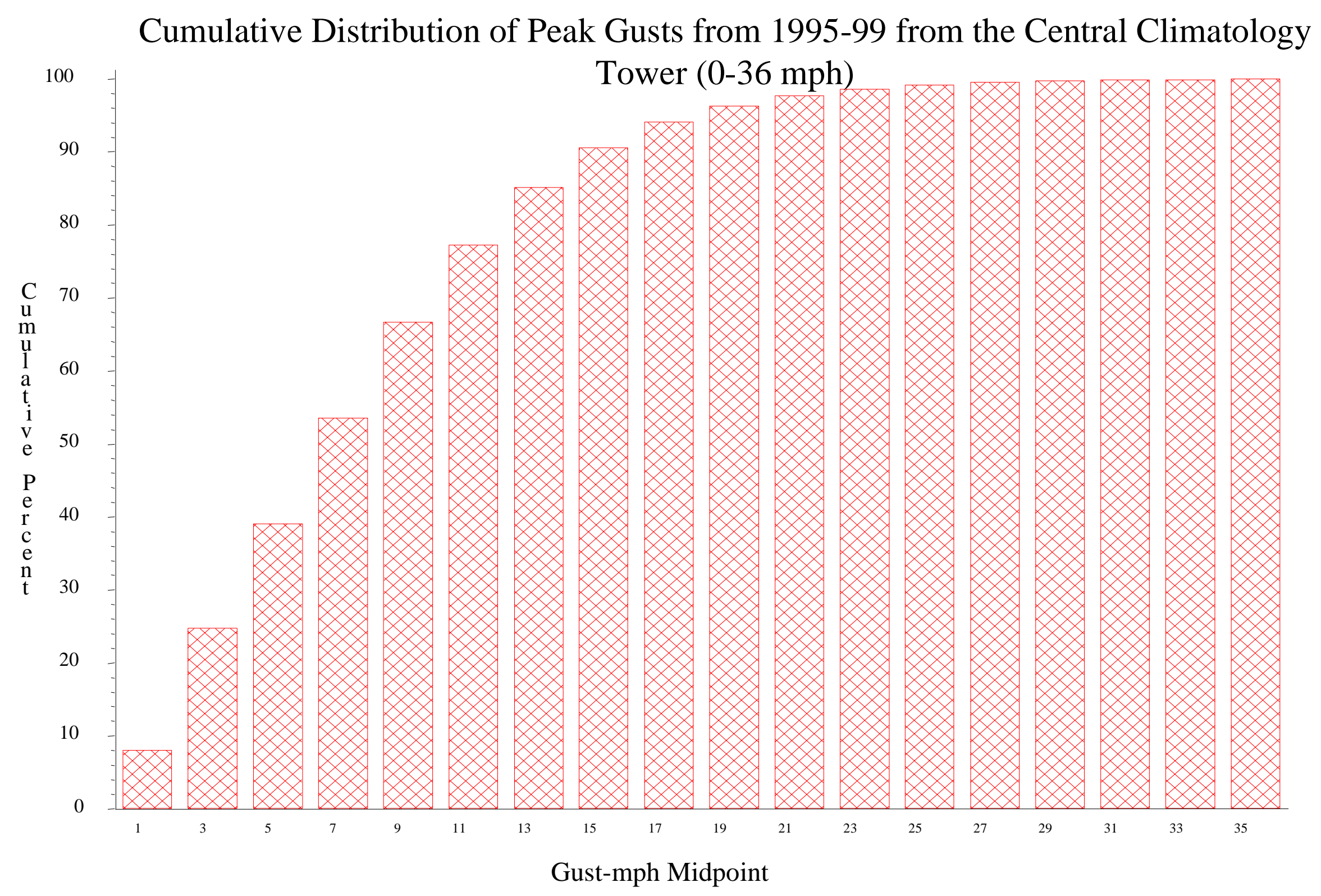

Figure 3. Cumulative Distribution of Peak Gusts for Five Years (1995-99) from the Central Climatology 4-meter Level 


\section{Central Climatology 4-Meter 1995-99 Speed Distribution}

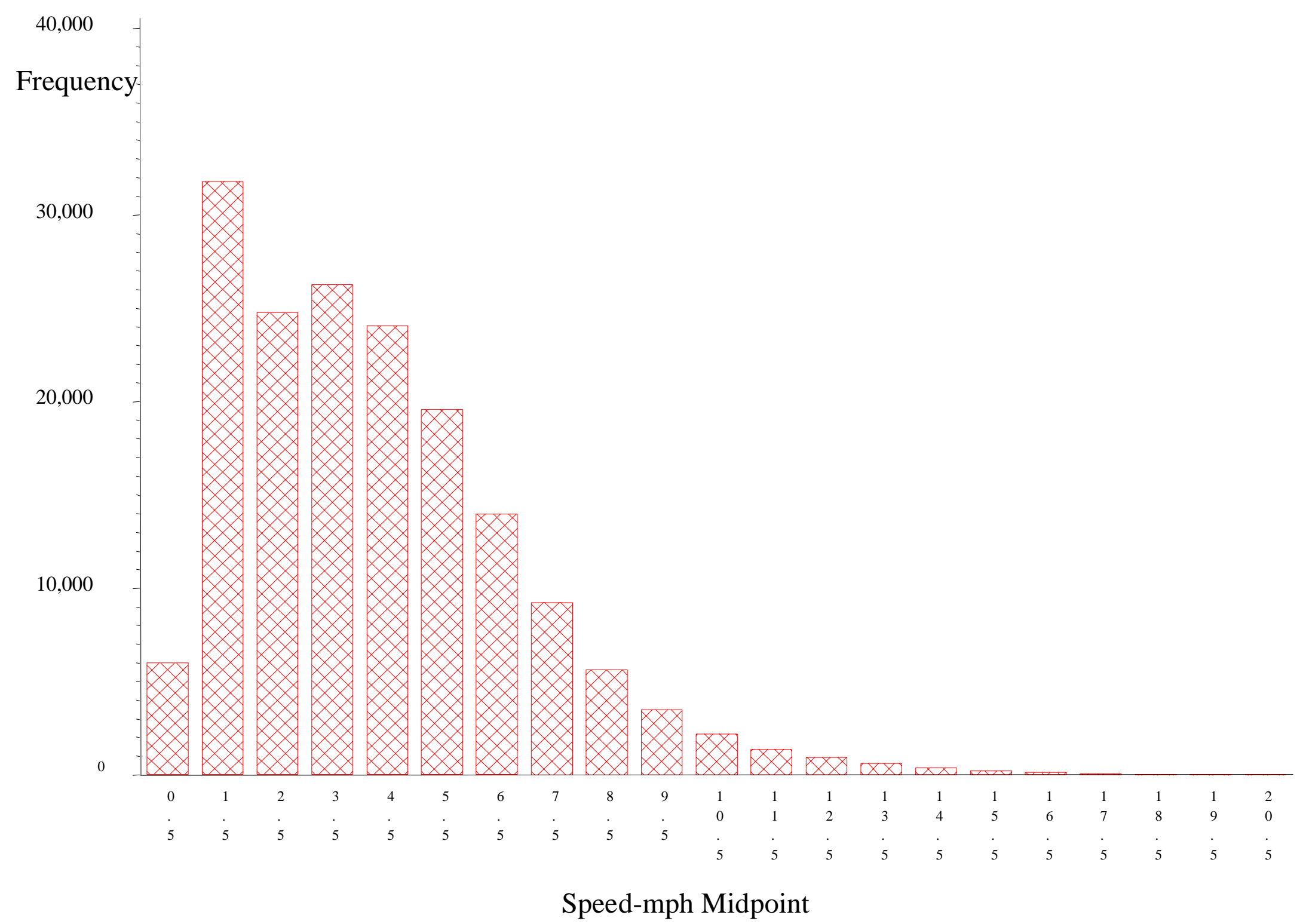

Figure 4. Distribution of 15-min Averaged Speed for Five Years (1995-99) from the Central Climatology 4-meter Level (1-35 mph) 
CC-4M 95-99 Fifteen-Minute Averaged Wind Speed Distribution (18 mph - 80 mph)

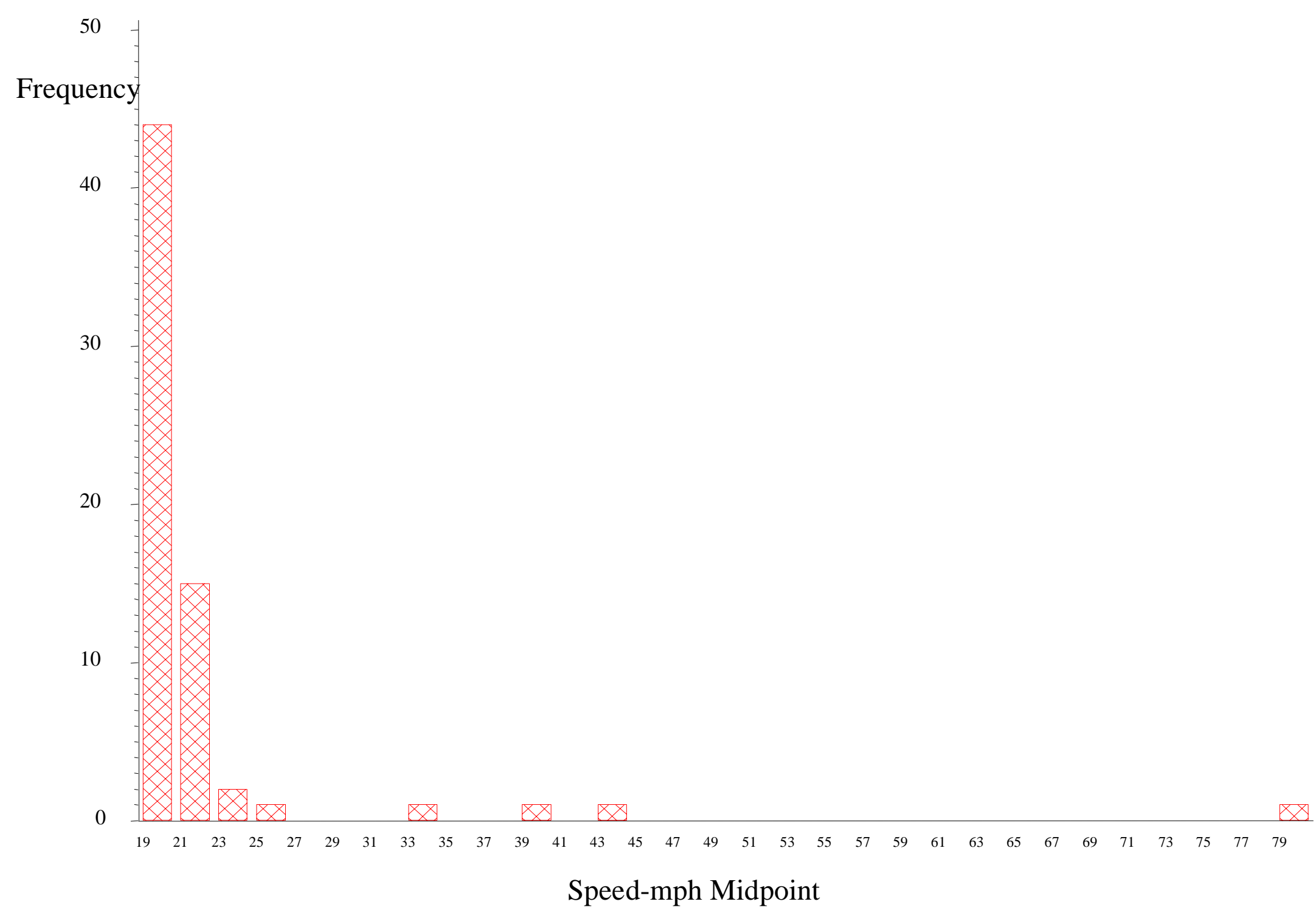

Figure 5. Distribution of 15-min Averaged Wind Speed for Five Years (1995-99) from the Central Climatology 4-meter Level (18-80 mph) 


\section{CC-4M 95-99 15-Min Averaged Wind Speed Cumulative Distribution (0 mph - 26 mph)}

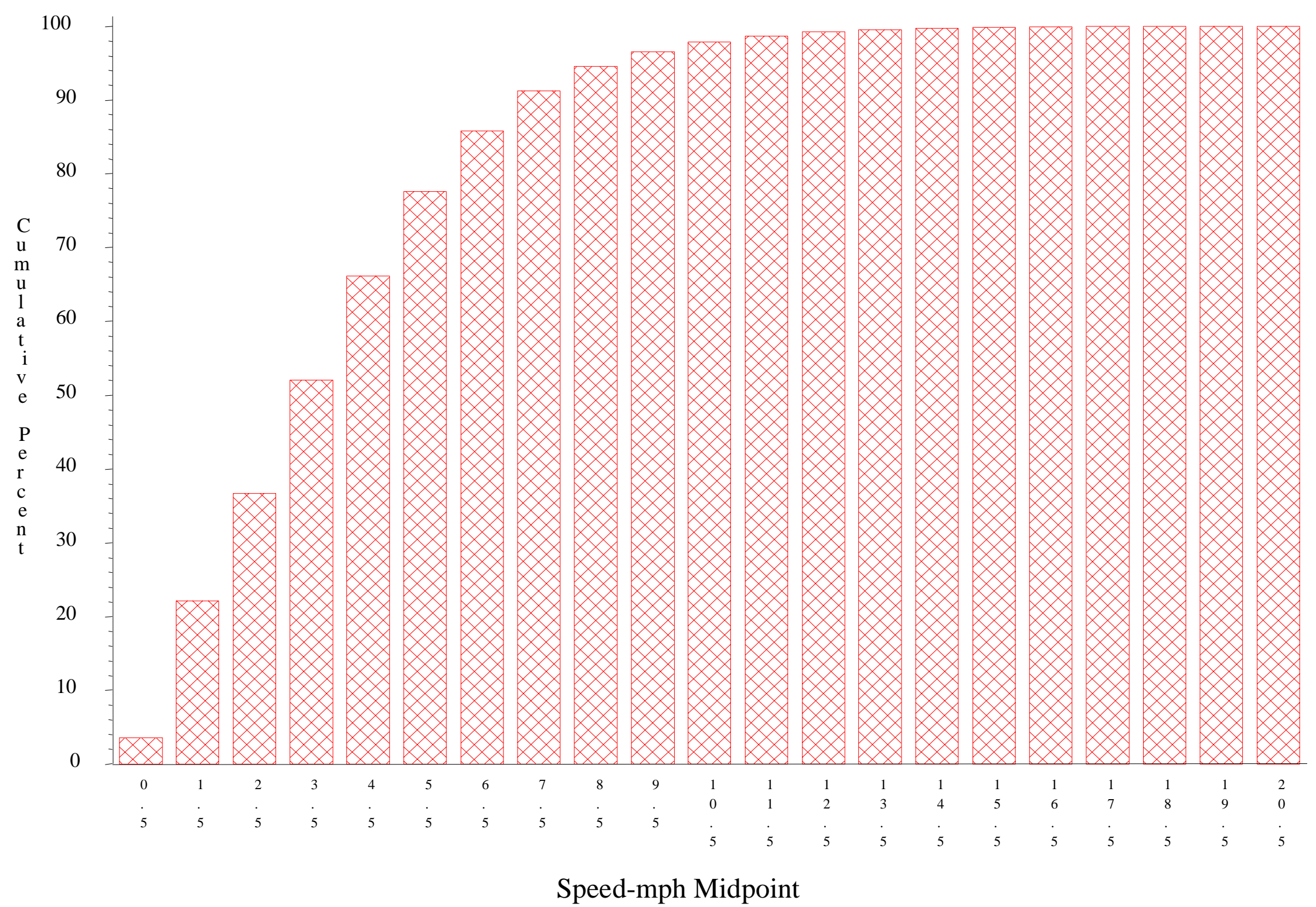

Figure 6. Cumulative Distribution of 15-min Averaged Wind Speed for Five Years (1995-99) from the Central Climatology 4-meter Level 


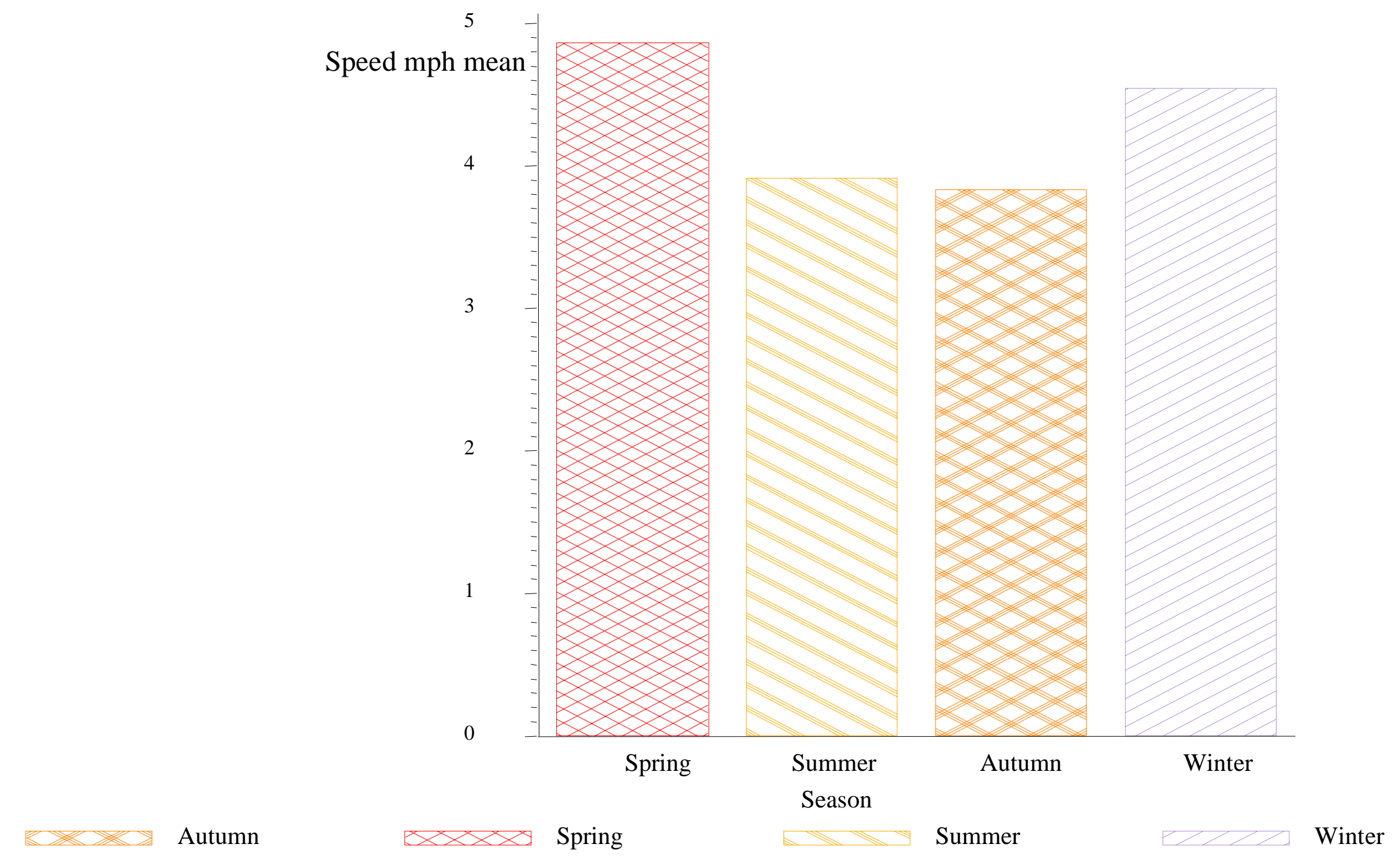

Figure 7. Distribution of 15-min Averaged Speeds by Season (Central Climatology 4-m level, 95-99) 


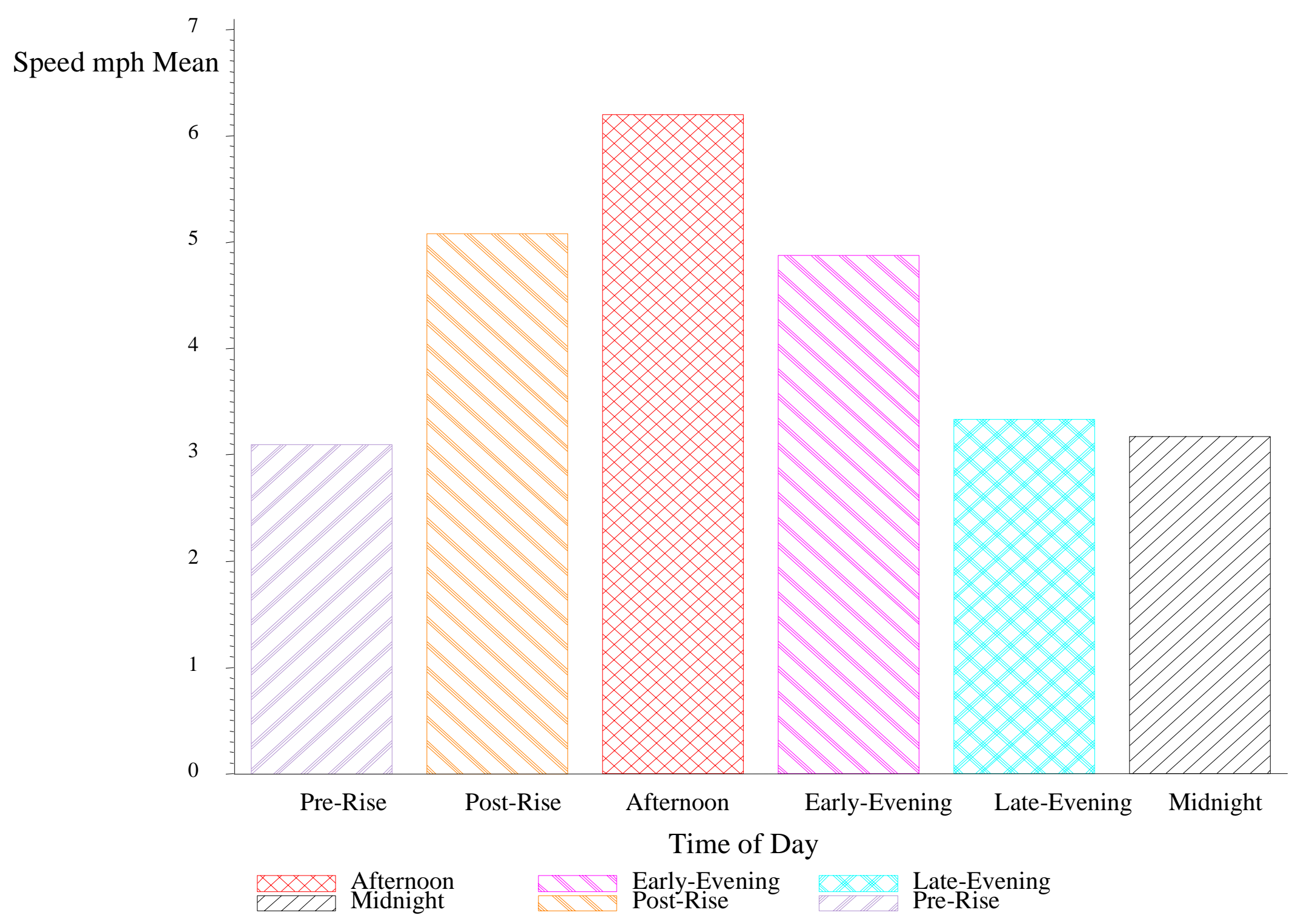

Figure 8. Distribution of 15-min Averaged Speeds by Time of Day (Central Climatology 4-m level, 95-99) 


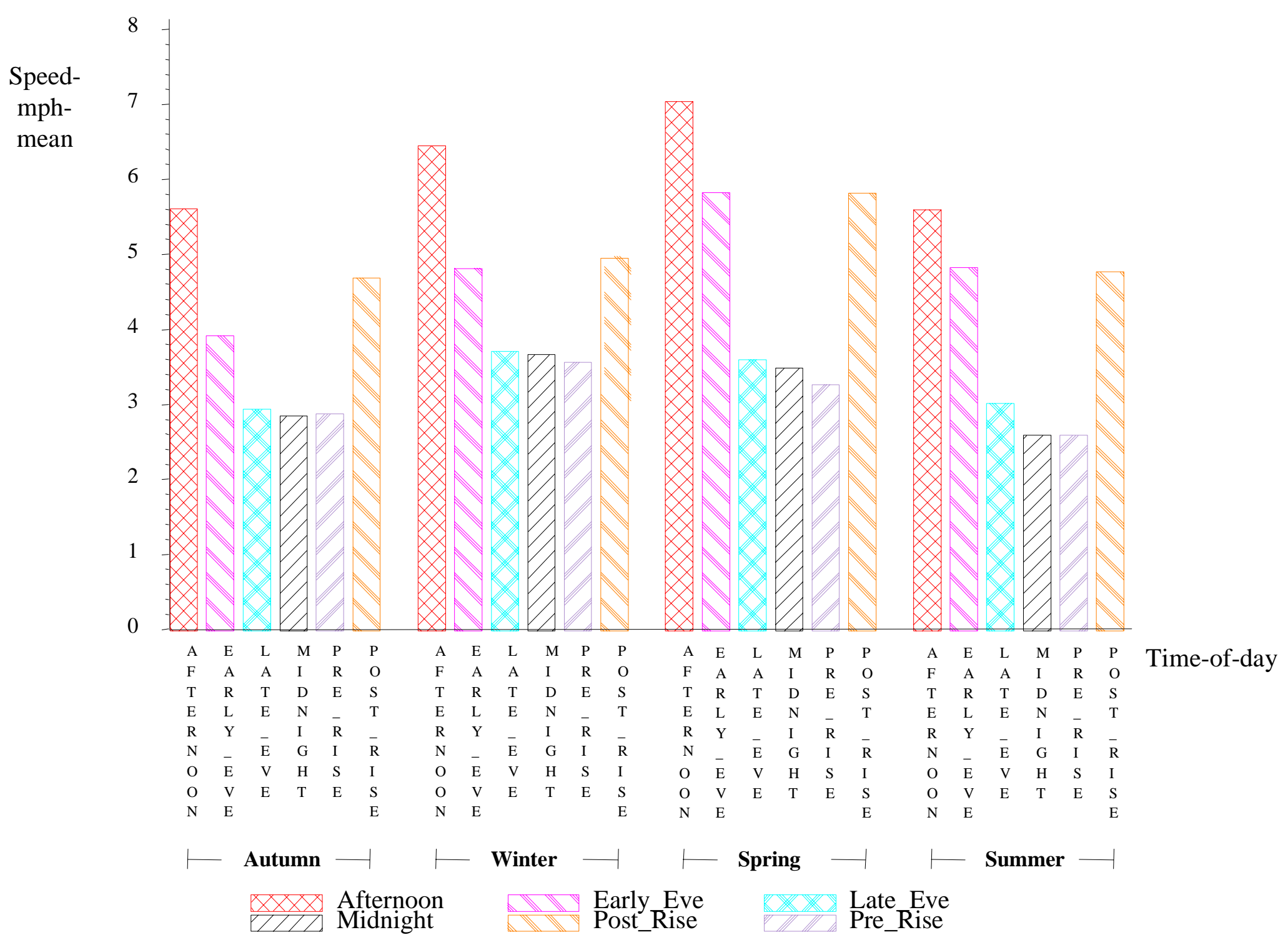

Figure 9. Distribution of 15-min Averaged Speeds by Season and Time-of-day (Central Climatology 4-m level, 95-99) 


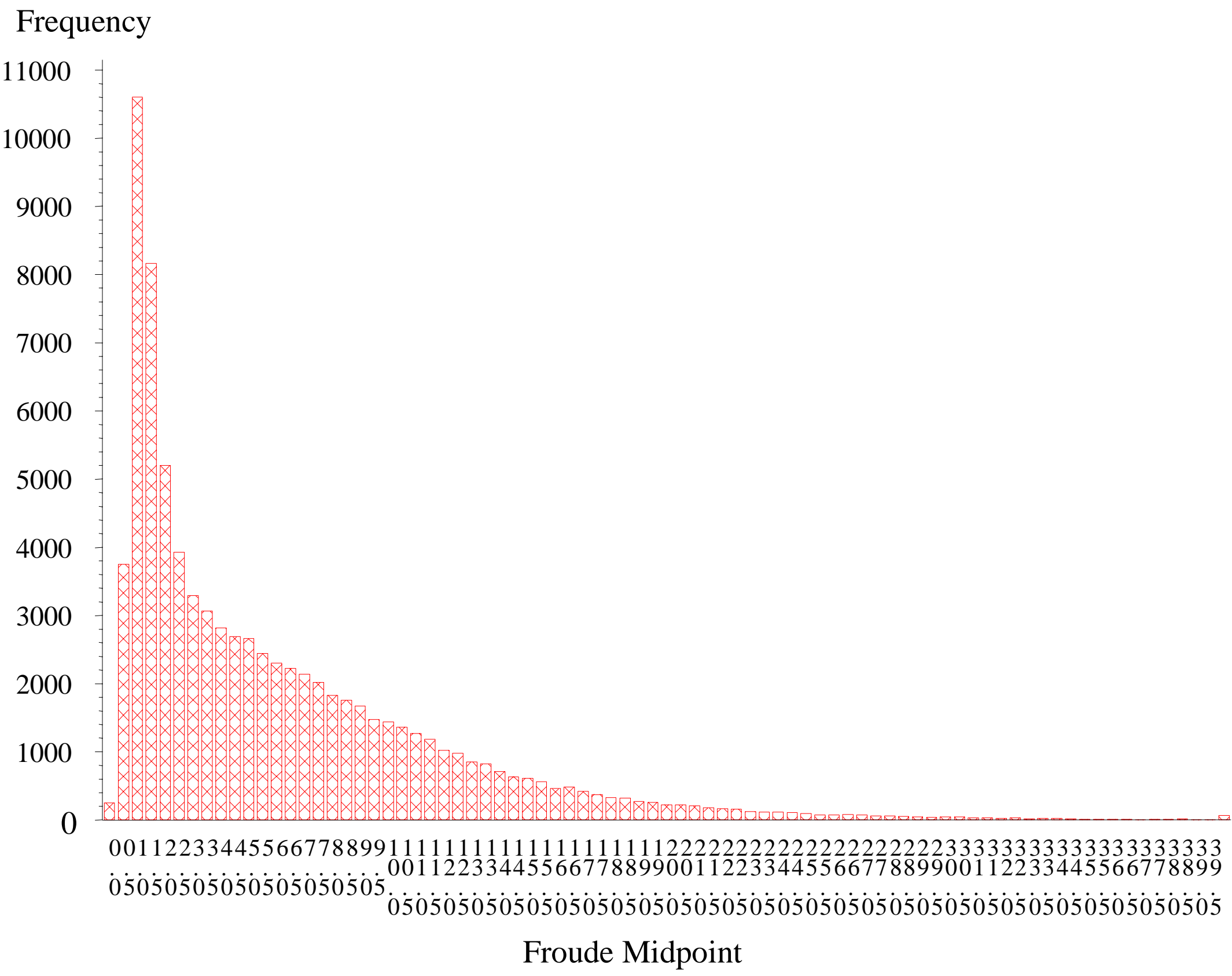

Fig. 10. Froude Number Distribution 


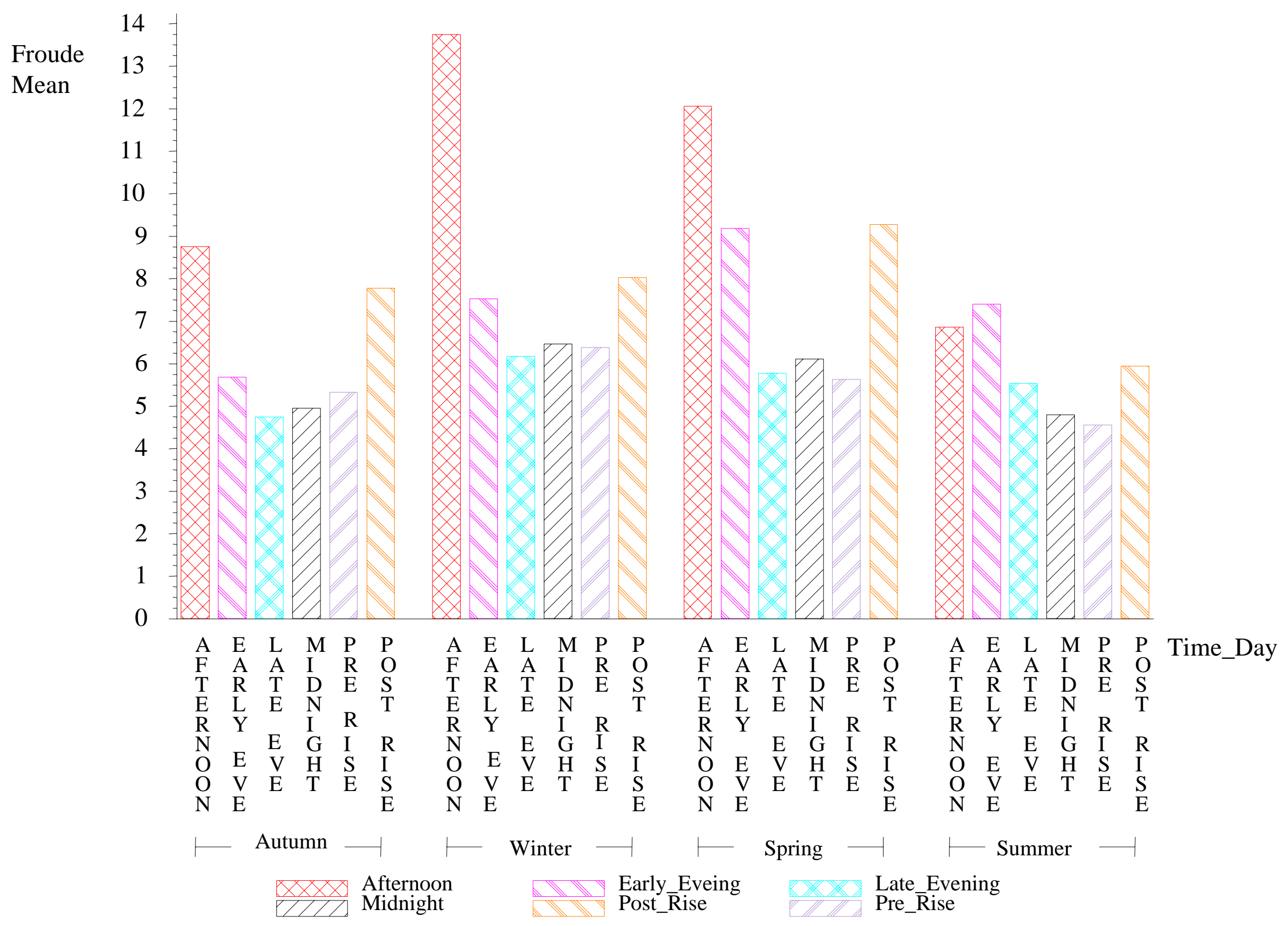

Fig. 11. Froude Number by Season and Time of Day 


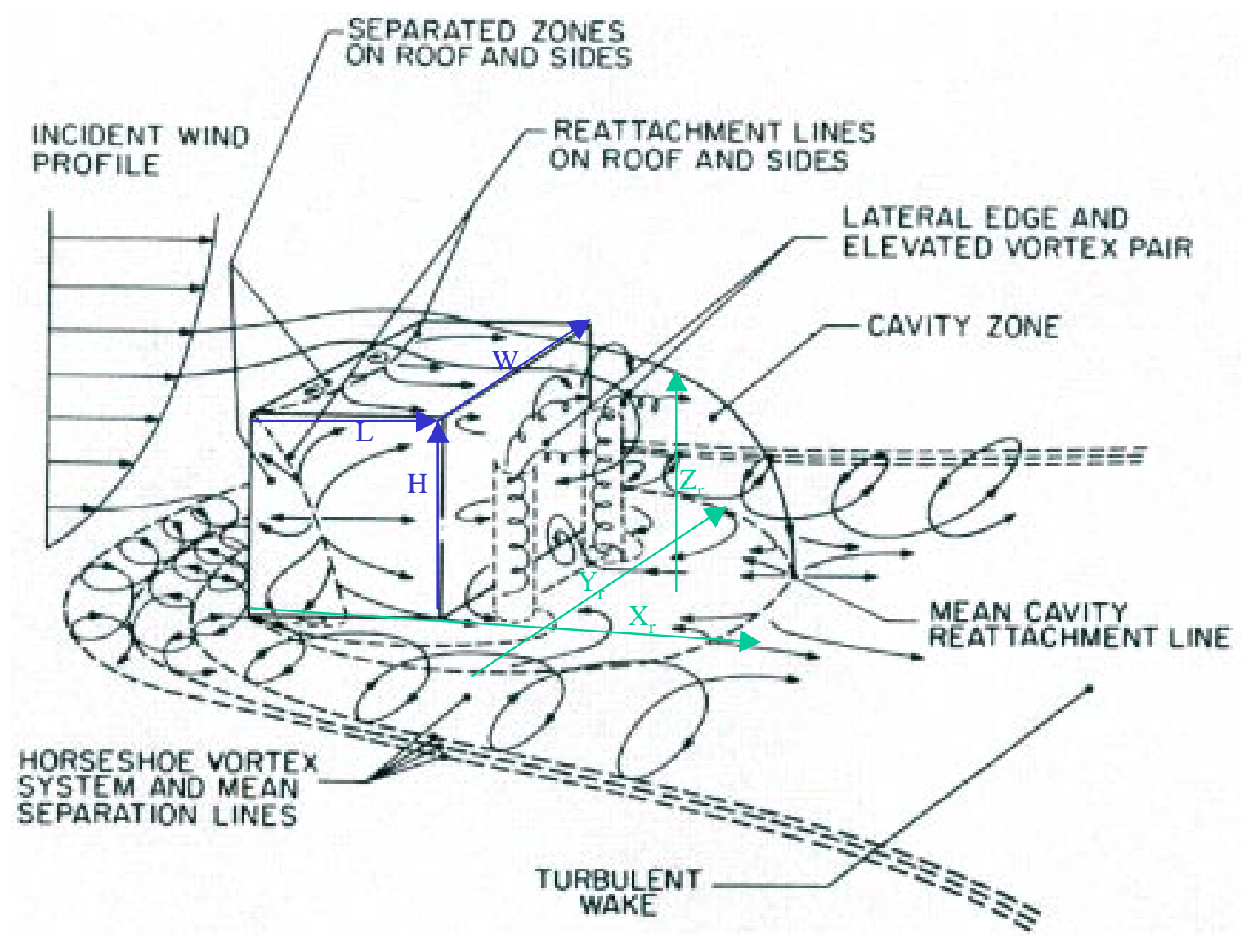

Fig. 12. Streamline patterns around a bluff body exposed to the incident wind. From Hosker (1984) (with permission). 

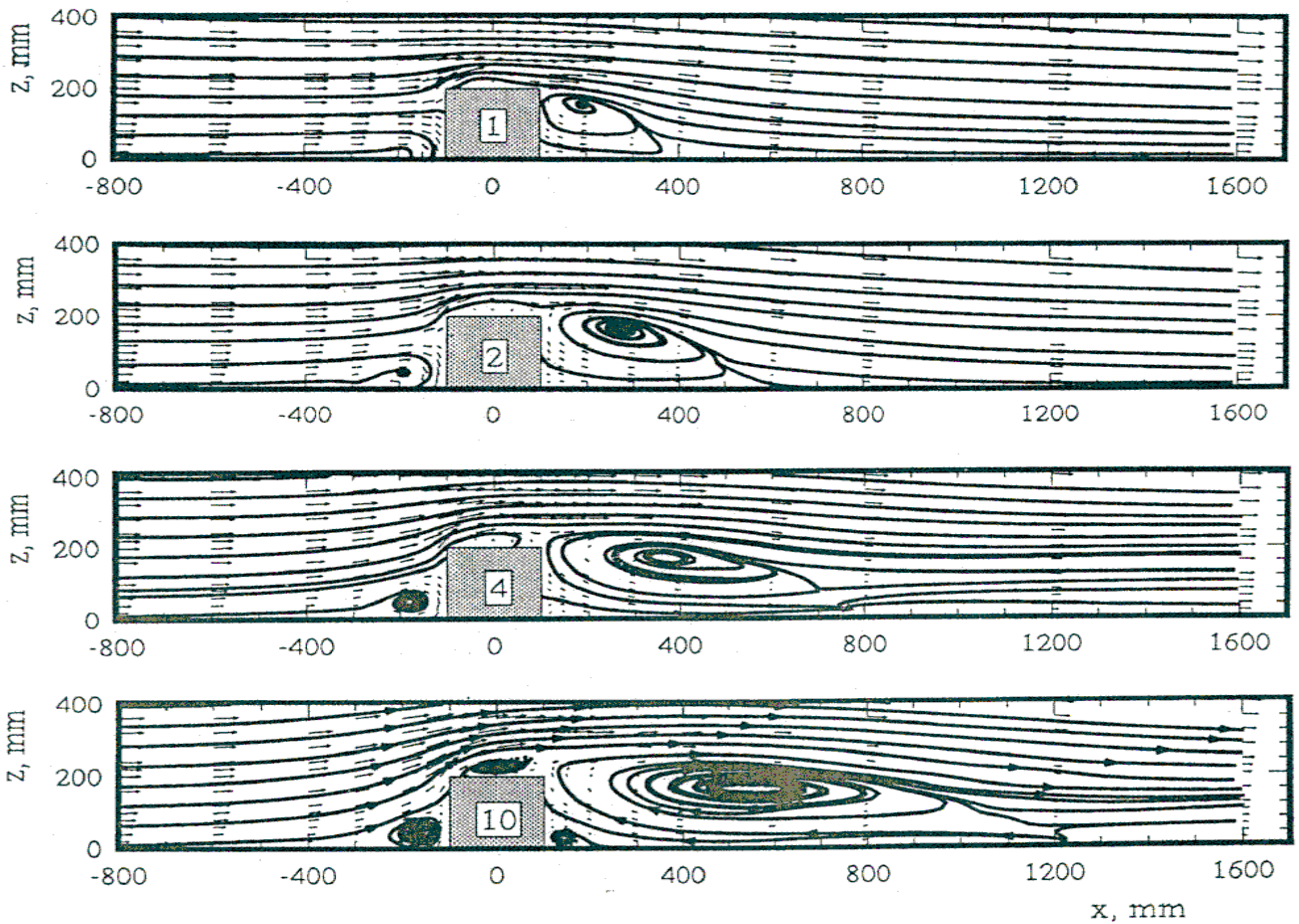

Fig. 13. Mean streamline patterns around a rectilinear building where the crosswind width (W) of the building is varied. The width to height ratio (in the light square) is being varied in each figure. From Snyder and Lawson (1996) (with permission). 

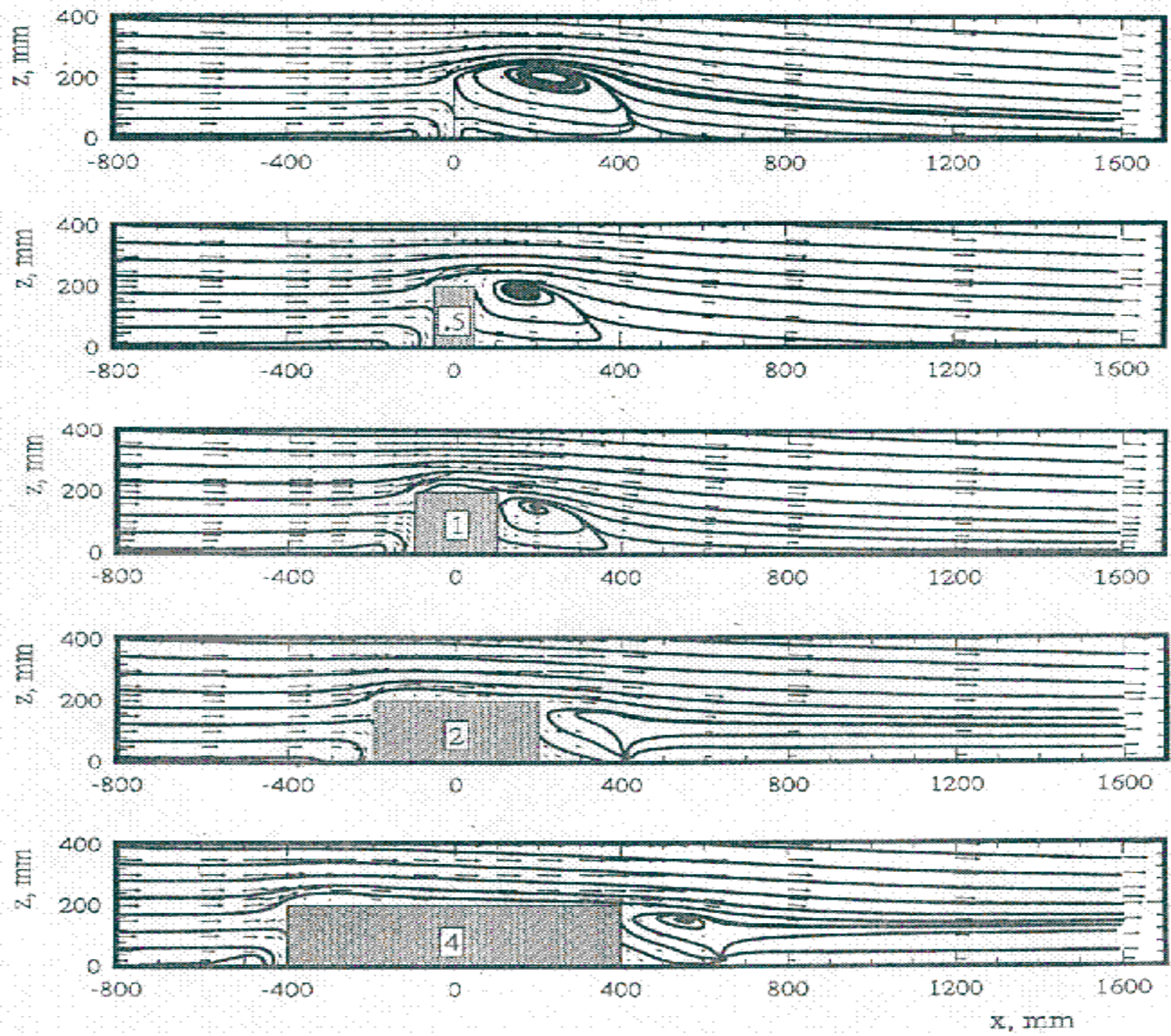

Fig. 14. Mean streamline patterns around a rectilinear building where the along-wind depth (D) of the building is varied. The depth to height ratio (in the light square) is being varied in each figure. From Snyder and Lawson (1996) (with permission). 

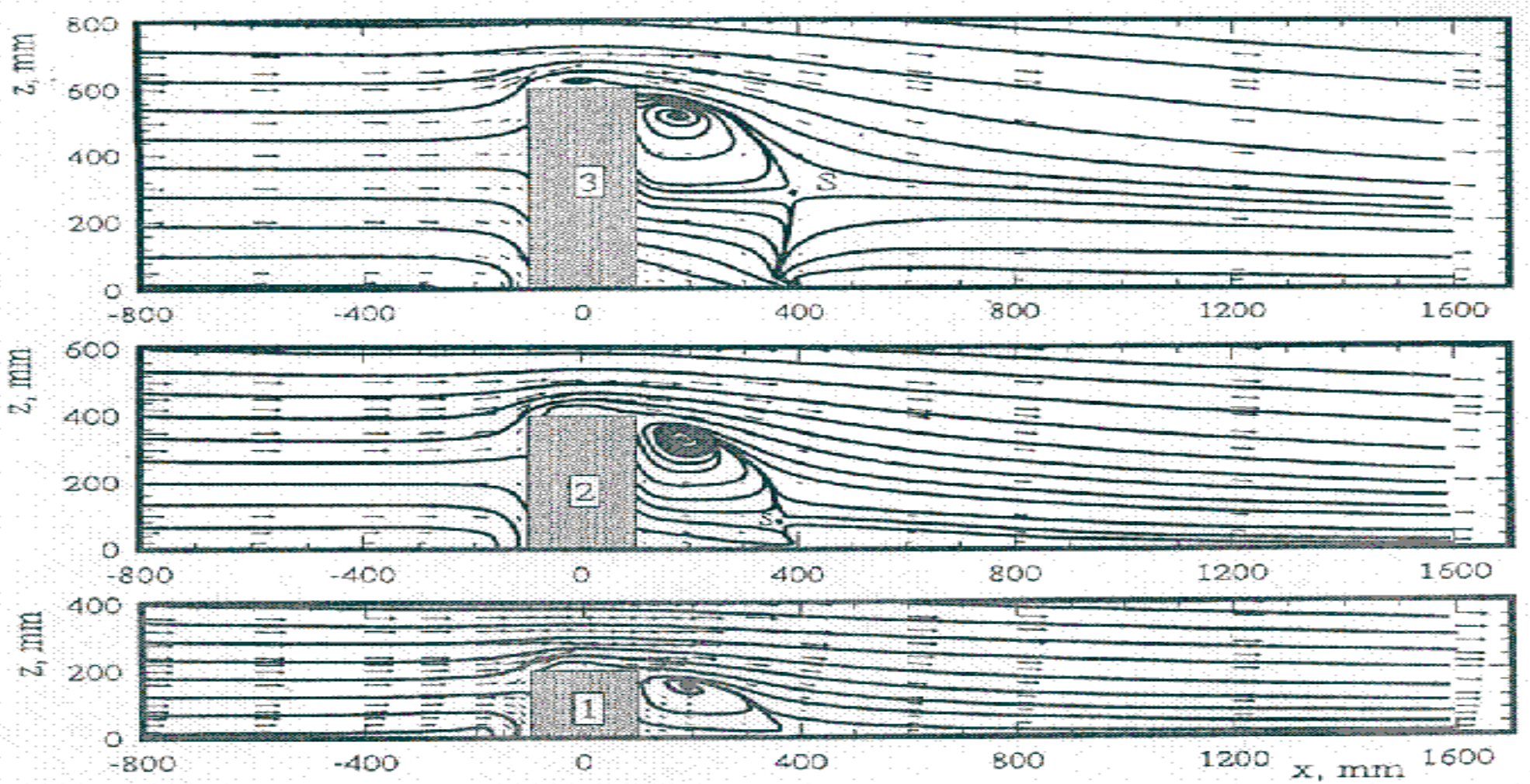

Figure 5. Streamline paterns around baildings of various heights. Number on building is $H / W$. L $=W$.

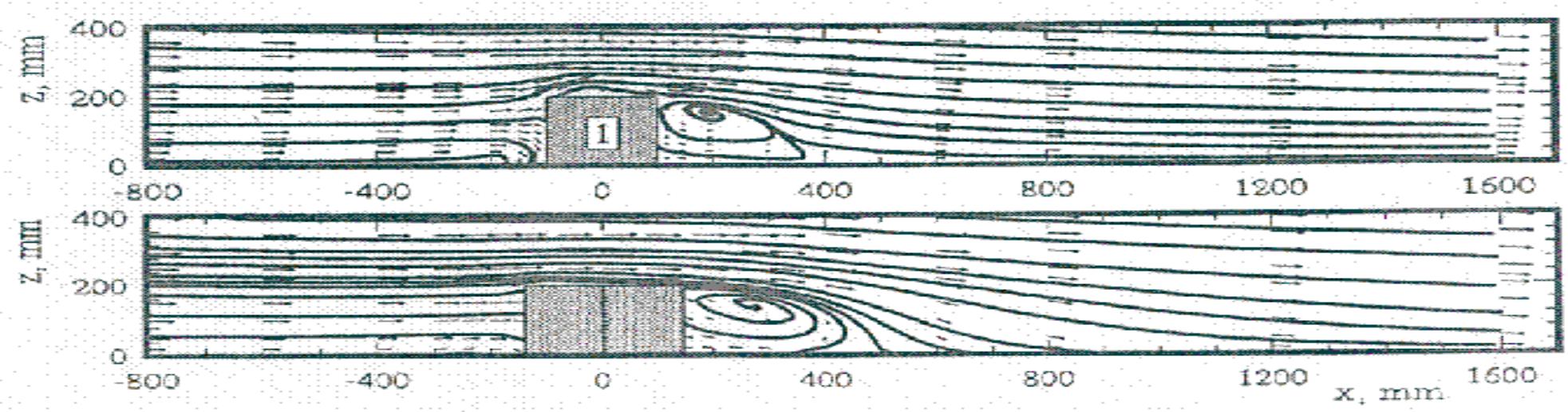

Fig. 15. Mean streamline patterns where the height $(\mathrm{H})$ of the building is varied (upper 3 panels). The height to depth ratio (in the light square) is being varied in each figure. Cubical building at $90^{\circ}$ and $45^{\circ}$ (lower 2 panels) with respect to the upwind flow. From Snyder and Lawson (1996) (with permission). 


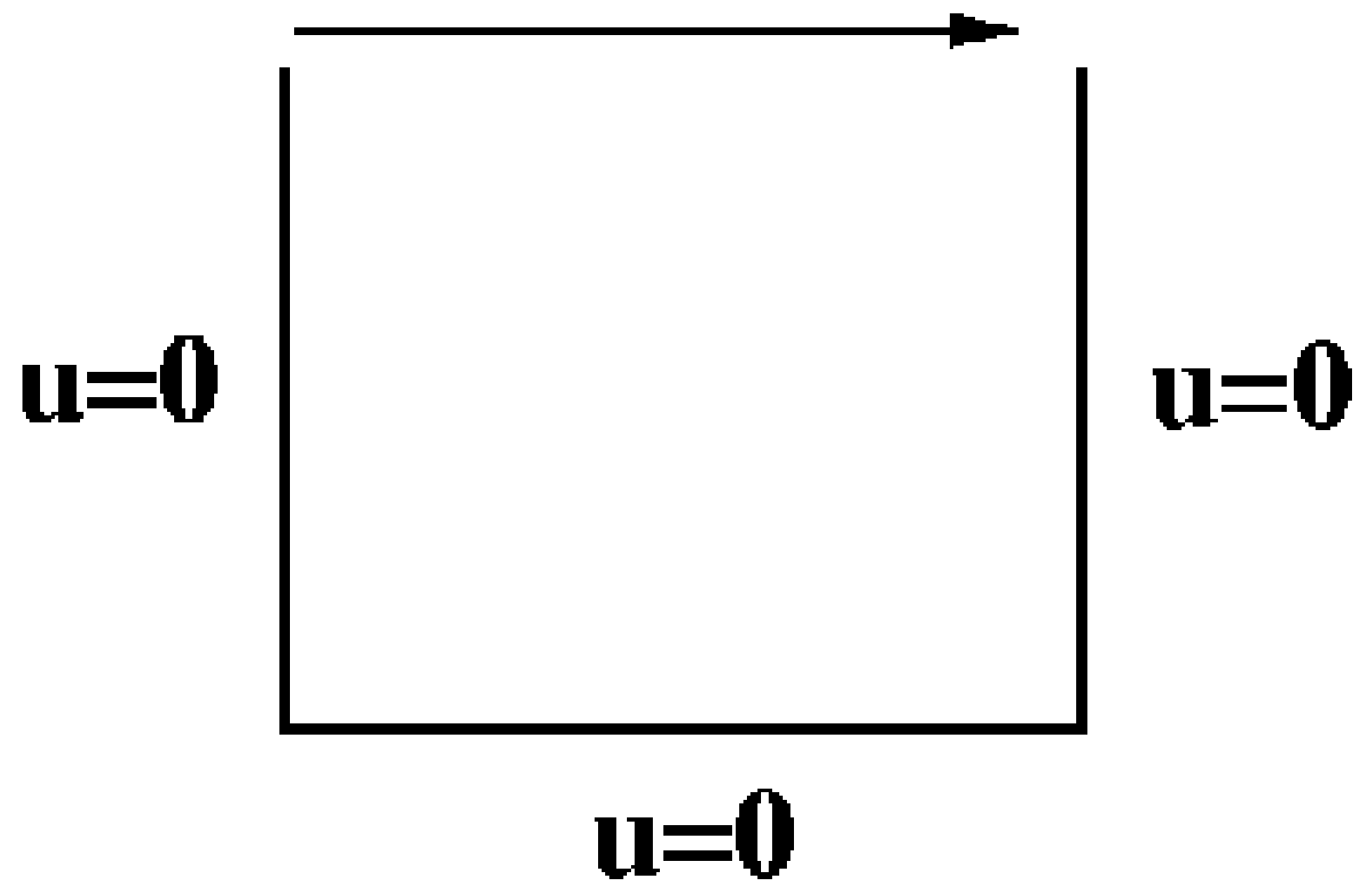

Fig. 16. Boundary conditions for driven cavity flow. 


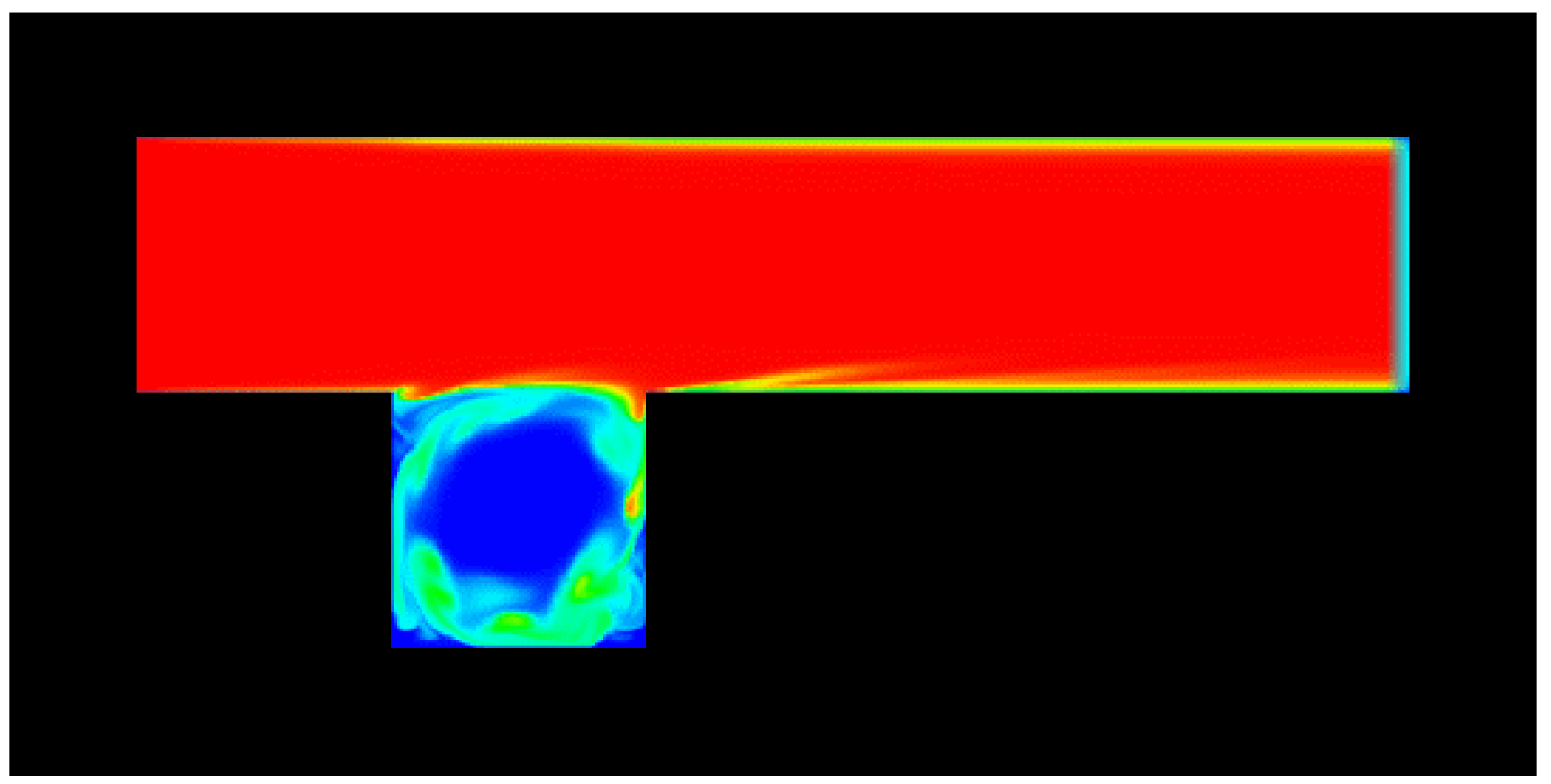

Fig. 17. Driven cavity flow (wind over a cubical windbreak). Flow visualization using temperature. Legend: Temperatures are relative. Red: highest; yellow: high; green: moderate; blue: lowest. 


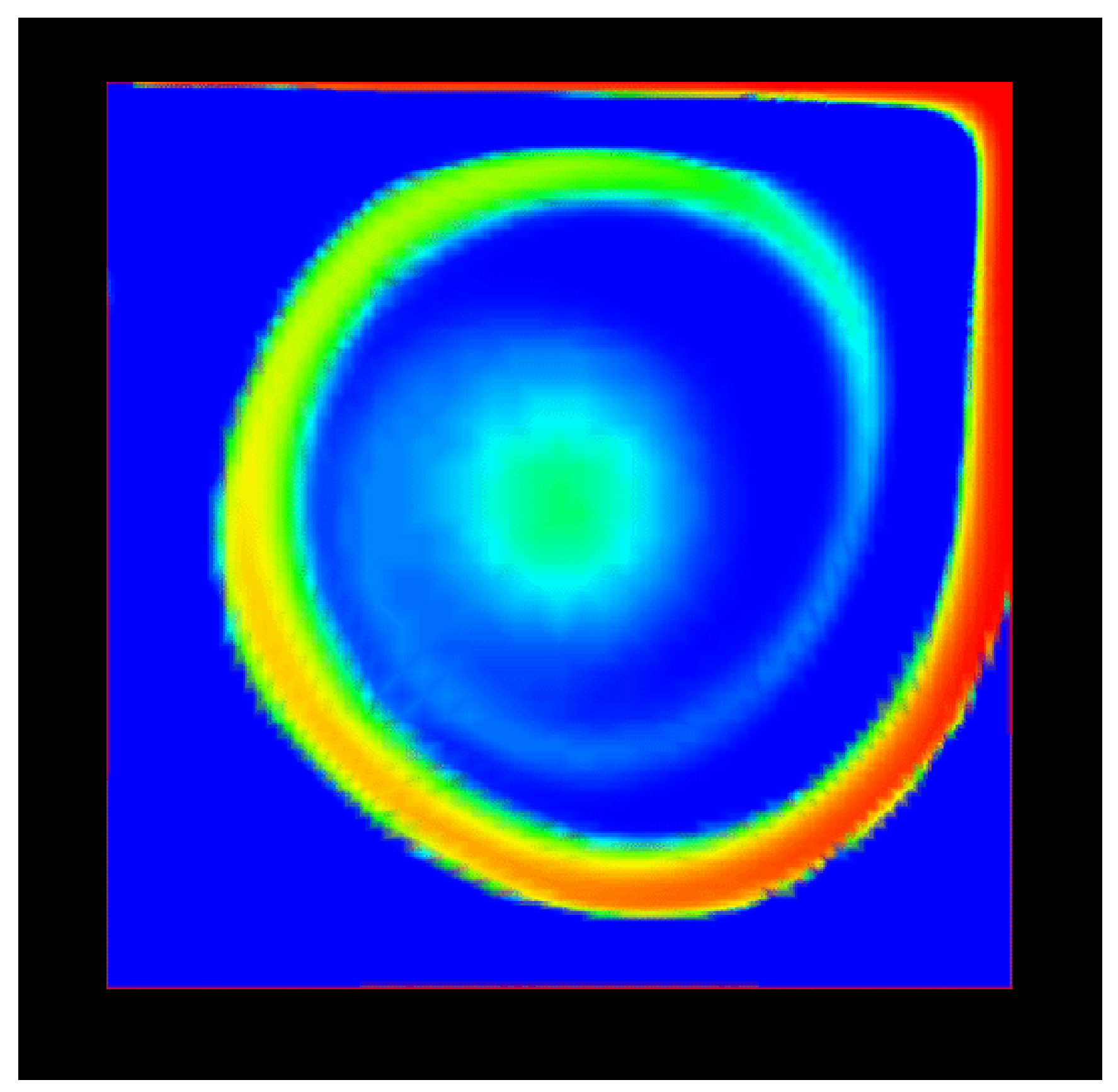

Fig. 18. An open-roofed cavity with height to depth ratio $1 / 1$. Flow visualization using temperature. Legend: Temperatures are relative. Red: highest; yellow: high; green: moderate; blue: lowest. 


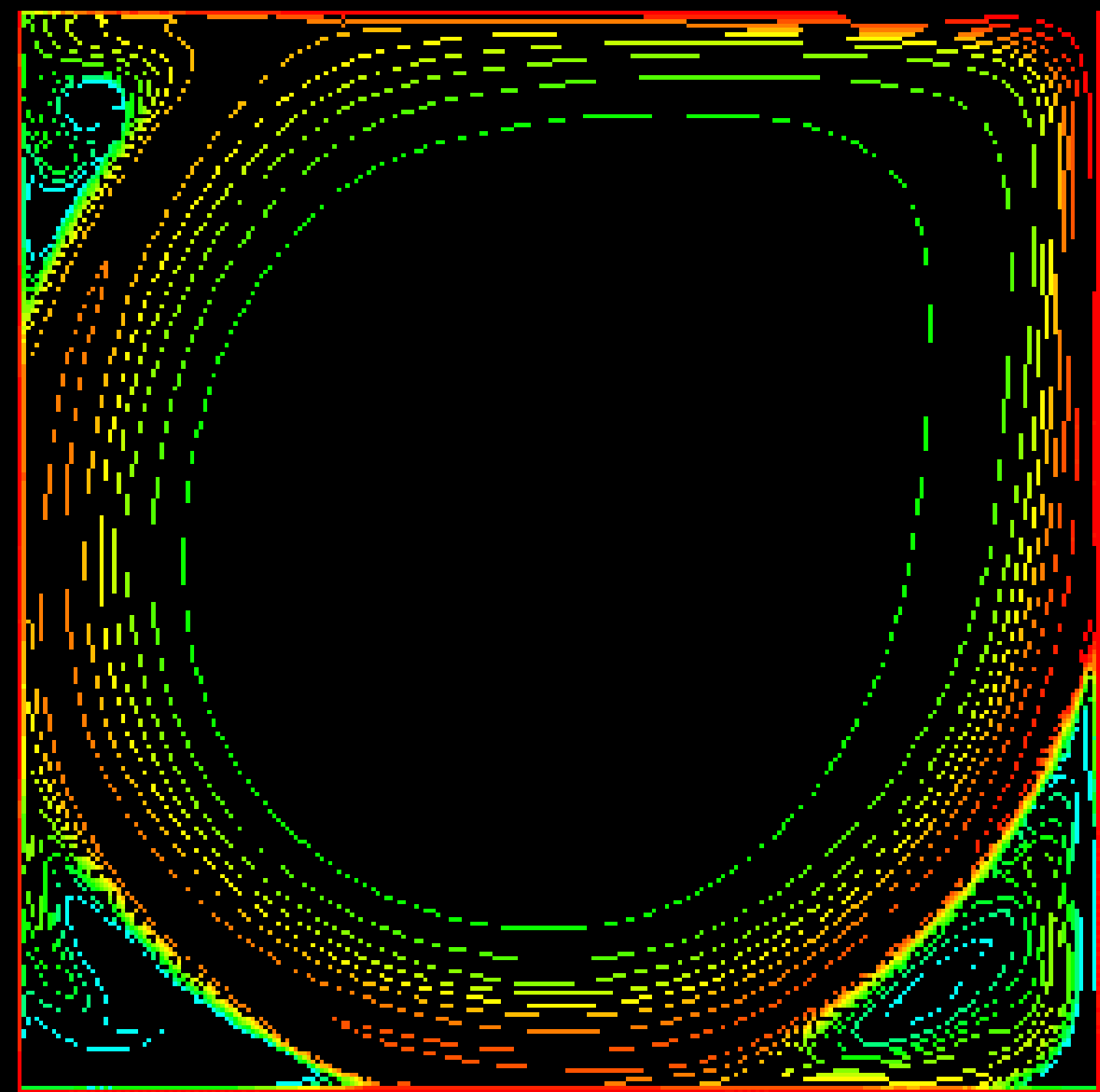

Fig 19. An open-roofed cavity with height to depth ratio 1/1. Flow visualization using isotherms.

Legend: Temperatures are relative. Red: highest; yellow: high; green: moderate; blue: lowest. 


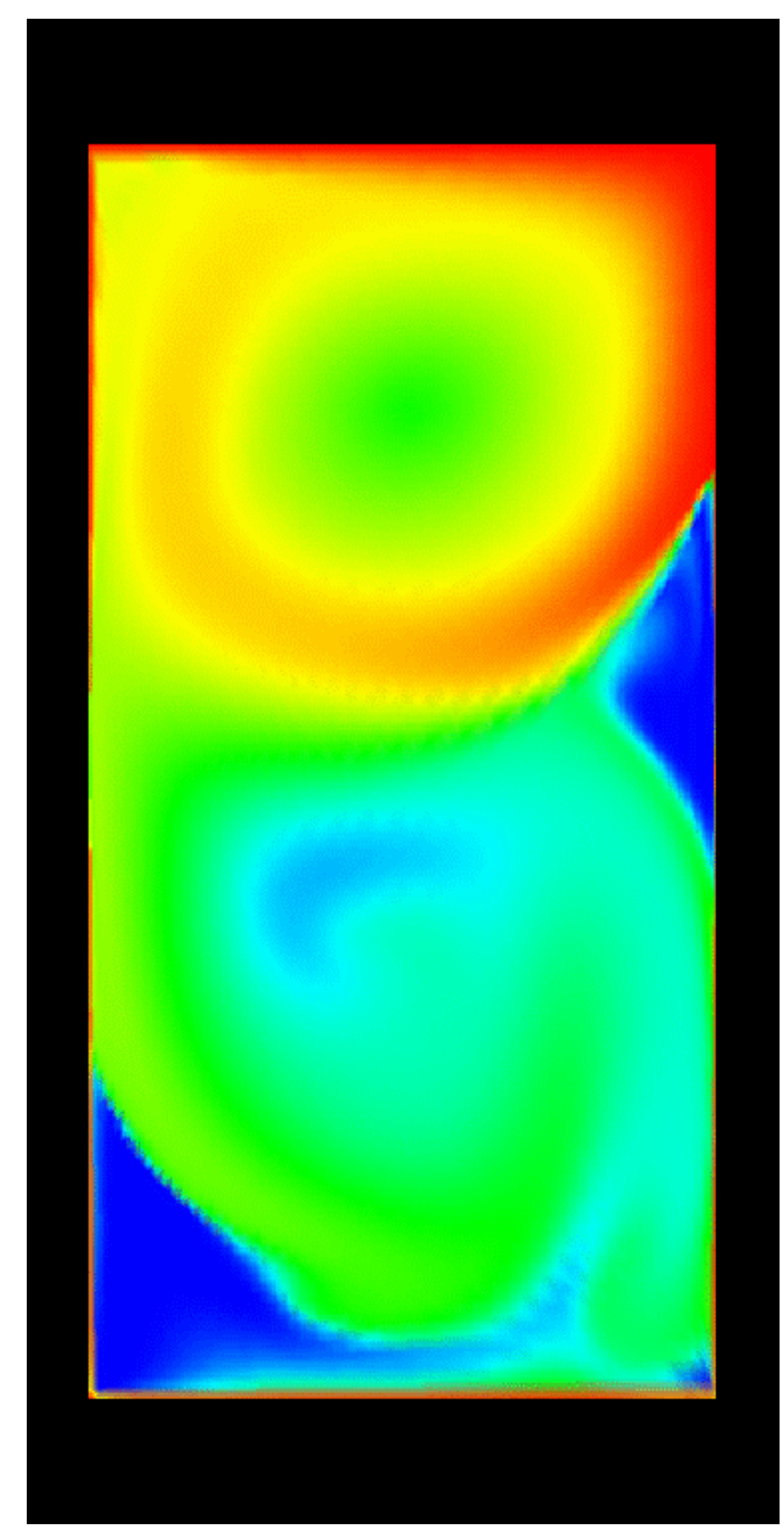

Fig 20. An open-roofed cavity with height to depth ratio $2 / 1$. Flow visualization using temperature.

Legend: Temperatures are relative. Red: highest; yellow: high; green: moderate; blue: lowest. 


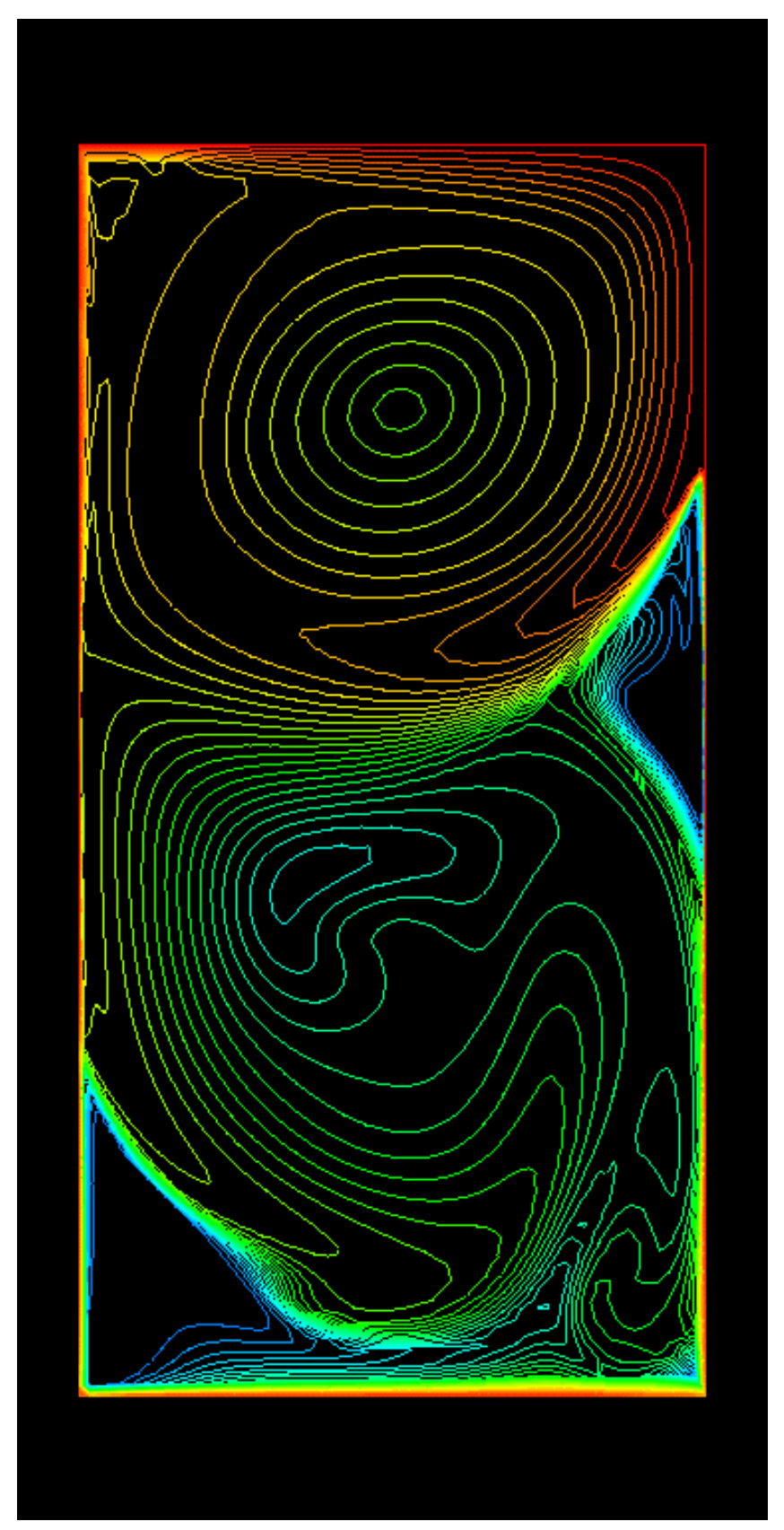

Fig 21. An open-roofed cavity with height to depth ratio 2/1. Flow visualization using isotherms. Legend: Temperatures are relative. Red: highest; yellow: high; green: moderate; blue: lowest. 


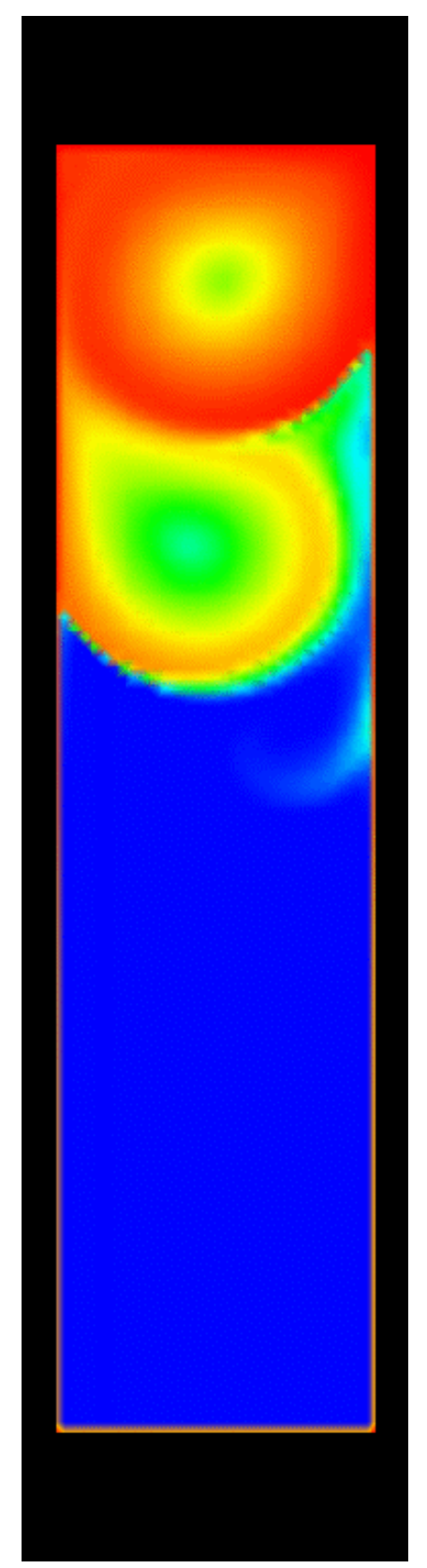

Fig 22. An open-roofed cavity with height to depth ratio 4/1. Flow visualization using temperature. Legend: Temperatures are relative. Red: highest; yellow: high; green: moderate; blue: lowest. 


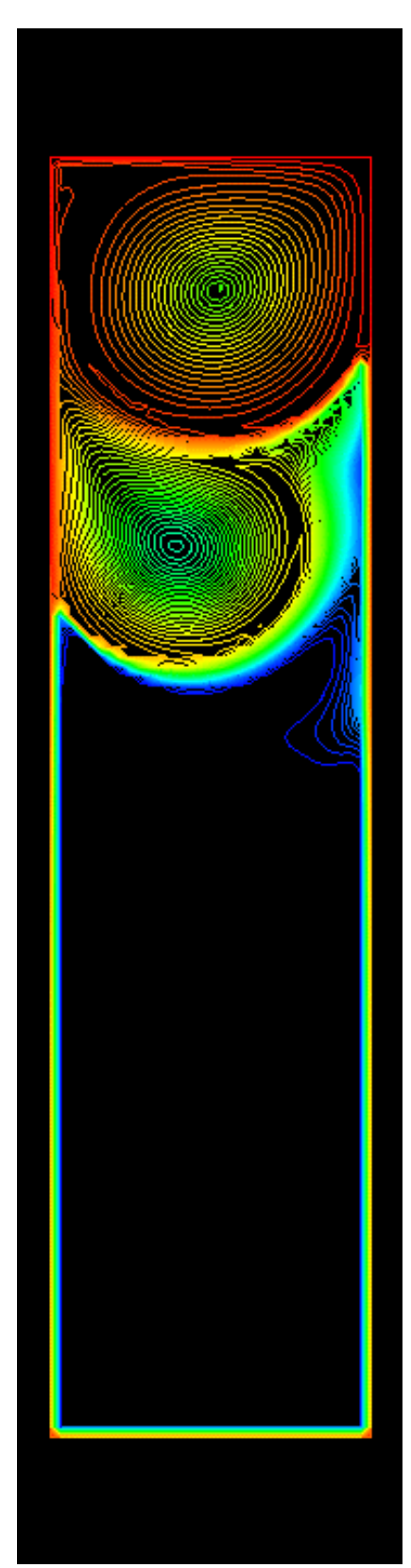

Fig 23. An open-roofed cavity with height to depth ratio 4/1. Flow visualization using isotherms. Legend: Temperatures are relative. Red: highest; yellow: high; green: moderate; blue: lowest. 